Article

\title{
Decision-Making Process for Photovoltaic Solar Energy Sector Development using Fuzzy Cognitive Map Technique
}

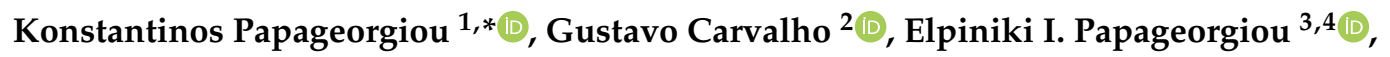 \\ Dionysis Bochtis ${ }^{4}(\mathbb{D})$ and George Stamoulis ${ }^{1}$ \\ 1 Department of Computer Science, University of Thessaly, Lamia 35100, Greece; gs@uth.gr \\ 2 Faculty of Economics, Business Administration and Accounting, University of Sao Paulo (USP), \\ São Paulo 05508-010, Brazil; gustavocarvalho@usp.br \\ 3 Faculty of Technology, University of Thessaly, Geopolis Campus, Larissa 41500, Greece; \\ elpinikipapageorgiou@uth.gr \\ 4 Institute for Bio-economy and Agri-technology (iBO), Center for Research and Technology - Hellas (CERTH), \\ Thessaloniki 57001, Greece; d.bochtis@certh.gr \\ * Correspondence: konpapageorgiou@uth.gr
}

Received: 25 February 2020; Accepted: 16 March 2020; Published: 19 March 2020

\begin{abstract}
Photovoltaic Solar Energy (PSE) sector has sparked great interest from governments over the last decade towards diminution of world's dependency to fossil fuels, greenhouse gas emissions reduction and global warming mitigation. Photovoltaic solar energy also holds a significant role in the transition to sustainable energy systems. These systems and their optimal exploitation require an effective supply chain management system, such as design of the network, collection, storage, or transportation of this energy resource, without disregarding a country's certain socio-economic and political conditions. In Brazil, the adoption of photovoltaic solar energy has been motivated not only by the energy matrix diversification but also from the shortages, problems, and barriers that the Brazilian energy sector has faced, lately. However, PSE development is affected by various factors with high uncertainty, such as political, social, economic, and environmental, that include critical operational sustainability issues. Thus, an elaborate modelling of energy management and a well-structured decision support process are needed to enhance the performance efficiency of Brazilian PSE supply chain management. This study focuses on the investigation of certain factors and their influence on the development of the Brazilian PSE with the help of Fuzzy Cognitive Maps. Fuzzy Cognitive Map is an established methodology for scenario analysis and management in diverse domains, inheriting the advancements of fuzzy logic and neural networks. In this context, a semi-quantitative model was designed with the help of various stakeholders from the specific energy domain and three plausible scenarios were conducted in order to support a decision-making process on PSE sector development and the country's economic potential. The outcome of this analysis reveals that the development of the PSE sector in Brazil is mainly affected by economic and political factors.
\end{abstract}

Keywords: Fuzzy Cognitive Maps; photovoltaic solar energy; scenario analysis; decision-support; energy management

\section{Introduction}

Fuzzy cognitive maps (FCMs) were introduced by Kosko (1986) as a methodology for modelling complex, dynamic systems [1]. In terms of structure, FCM is a directed weighted graph with feedback loops, which consists of nodes (concepts) and strength connections (relationships) among nodes [2]. An FCM models the system in the form of a graph, introducing causal relations between concepts and 
represents the system's behavior using the accumulated knowledge, perceptions, experiences or beliefs from experts, stakeholders or both [3,4], usually expressed in natural language.

Over the last years, FCMs have attained great attention and popularity since they are able to implement modelling, analyzing and simulating tasks, as well as test the influence of parameters and predict the behavior of the examined system [2]. Furthermore, they include learning capabilities and characteristics as they can learn from historical data and previous knowledge to overcome the subjectivity of experts' opinions [5-7]. In other words, it is a semi-quantitative method that uses qualitative knowledge from experts and stakeholders to form FCM-based models and further increase system understanding and reduce uncertainties.

The task of simulation is incorporated by FCMs and can help managers to increase system understanding and reduce uncertainties about how the studied phenomenon may respond to changes in the main system drivers [8].

Among other fields, FCMs are also used for scenario planning even if they were not initially used for this purpose [9]. Kok [10], Van Vliet et al. [11] and Jetter and Schweinfort [12] have introduced FCM-based scenarios to improve the quality of scenarios and increase the robustness of the scenario development step.

Over the last two decades, renewable energy has been considered a vital candidate in global power demand [13], and thus, its exploitation needed to be well explored and studied. However, due to several limitations, such as environmental problems and because of the high uncertainty that these kinds of systems present, the renewable energy sector is considered highly non-linear and complex. In this context, Fuzzy Cognitive Map is a method that can illustrate the uncertainty causality [14] and becomes a powerful tool to model such complex systems that involve many factors [2]. Due to this fact, FCM has been recently deployed in a renewable energy domain with great perspectives.

Taking one step further, FCMs have recently implemented management and decision-making tasks in the Energy sector [9,15]. In particular, in [15], an FCM approach was applied to predict and analyze the consequences of Brexit for the Energy-Water-Food (EWF) demand, examining different Brexit scenarios. FCMs can deal with complex problems, vast domains of inherent uncertainties [16] and processes like decision making that are based on human reasoning process [2,17]. In [18] and [19], special attention has been given to FCMs for management, decision-making and prediction purposes in the energy context. Specifically, the authors in [18] have proposed an algorithm based on Artificial Neural Networks (ANN) to create a model for monthly gasoline consumption estimation. The produced results could help officials and producers for better planning and marketing as well as optimizing gasoline production. An FCM has been proposed in [20] as a powerful inference tool to model the complex system of the electricity market. In this context, the authors describe the structure of FCMs and examine the way they are used to model and simulate competitive trading markets. Thus, certain approaches will be selected to further increase the understanding of how such markets behave in different circumstances. A Fuzzy logic-based framework was investigated in [21] for anomaly detection in energy consumption data where uncertainties inherent to forecasting, have been tackled. Regarding the renewable energy domain, a socio-economic analysis was conducted in [22], in which FCMs were employed to identify potential consequences over the mix of fossil fuel and renewable energy power sectors, as well as how certain policies that regard the energy domain can affect a country's economic growth. We also need to report on [23], in which an FCM methodology was applied for assessing energy efficiency strategies and electricity demand prediction, whereas Nikas et al., dealt with policy-making in the Renewable Energy sector, employing a stakeholder-driven approach based on FCMs [24]. Alipour et al., in a more recent study, explored the FCM capabilities on identifying and analyzing unpredictable factors that have a direct impact on solar photovoltaics in an uncertain socio-economic, political and technological environment [25]. It is worth mentioning that this is the first research study that implements FCM-based scenario analysis in the renewable energy field.

In order to tackle the vast amount of data, various parameters, modelling, learning, and simulation tasks of complex systems, researchers need a simple but powerful software tool that could help 
them in this direction. As found on the related literature, several tries occurred by researchers for developing a software product with simple or advanced functions that could perform either designing and analyzing tasks or even more complex functions like learning and simulation on FCM-based systems. Reviewing the existing literature, tools like Mental Modeler [26], FCMapper [27], ESQAPE [23], FCM Expert [28], FCM-Analyst [29], JFCM [30], and FCM Designer [31] can offer various capabilities and have their own unique specifications. However, MentalModeler [26] is the only web-based tool for scenario analysis and environmental modeling. This tool provides an opportunity to incorporate different types of knowledge into environmental decision-making, define hypotheses to be tested, and run scenarios to determine perceived outcomes of proposed policies.

However, a gap is noticed in the relevant literature, regarding the existence of a more user-friendly tool that could provide extra capabilities for aggregating FCM models and learning them using supervised and unsupervised algorithms. Considering this gap, the team of Papageorgiou E. has developed a new web-based tool, called FCMwizard [25], that incorporates these functionalities for helping research community to freely experiment with them and exploit all the capabilities offered. Some preliminary work with the use of the FCMWizard tool has been recently made in the environmental domain, dealing with decision making problems such as (i) the economic sustainability of poor women in rural areas [32] and (ii) climate change adaptations [33].

In this work, the FCM technique is applied to perform a decision-making process for PSE sector development, providing at the same time the researchers and the FCM community, wth an efficient simulation tool called FCMWizard, to conduct policy making simulations in their own case studies. In particular, the authors explore relevant FCM-based scenarios for the Brazilian Photovoltaic Solar Energy Sector (PSE) employing the FCMWizard tool. The PSE arises as one of the most promising renewable energy sources to replace fossil fuels [34], since climate and environmental changes, described by the scientific community [35], are increasing continuously. This happens as a result of the increasing energy demand that stems from technological progress and other advancements in human development. Scenario planning has proven to be the appropriate technique for institutions that are immersed in this PSE sector and need to make complex decisions, taking into account various uncertainties and risks, such as socio-political, environmental and technological.

The following tasks emphasize the novelty of this research work:

(i) to present the decision-making capabilities of the new FCMWizard tool for modelling stakeholders' perception in the complex sector of Renewable Energy, and

(ii) to develop and investigate various scenarios using an FCM-based simulation process, implemented by the new FCMWizard tool, regarding the development of PSE in Brazil.

The structure of the present paper is as follows: Section 2 briefly describes FCMs, while Section 3 presents the problem of PSE development in Brazil and the building process of the model. In Section 4, FCMWizard tool is adequately presented and its decision-making functionalities are reported accordingly. The scenarios development and analysis regarding the Brazilian PSE with the use of the FCMs are provided in Section 5. The discussion of the results is laid in the same section. The last section is devoted to the conclusions of this study.

\section{Fuzzy Cognitive Maps}

FCMs are fuzzy structures that combine fuzzy logic and Neural Networks, which incorporate knowledge acquisition and indicate the causality among concepts of complex systems that are characterized by uncertainty. FCMs were first introduced by Kosko [1] and since then they have been used to represent human knowledge and reasoning, while they serve as a method for modelling dynamic decision systems. Furthermore, learning techniques were later included to train FCMs and identify appropriate weights for its interconnections.

FCMs as we know them, are fuzzy signed directed graphs with feedback. They consist of concepts that are represented in the graph by nodes. Concepts are interconnected with directed arcs that are 
labelled with fuzzy values in the interval $[0,1]$ or $[-1,+1]$ and show the strength of impact between the concepts [36]. Typically, an FCM with $n$ nodes can be represented in the form of an adjacency matrix $\mathrm{W}_{n x n}$, where each element $w_{i j}$ of the matrix takes values within $[-1,+1]$.

The causal relationships (weights) between concepts have three possible types.

- $\quad$ Positive causality if $w_{i j}>0$, where Ci increases $C_{j}$

- $\quad$ Negative causality if $w_{i j}<0$, where Ci decreases $C_{j}$

- $\quad$ No causality between $C_{i}$ and $C_{j}$ if $w_{i j}=0$.

The FCM converges to an equilibrium point using one of the following calculation rules, (1)-(3), when values $X_{i}$ have been assigned to the concepts $C_{i}$ [37]:

$$
\left.\begin{array}{r}
\text { Kosko : } X_{i}^{(\kappa+1)}=f\left(\sum_{\substack{j=1 \\
j \neq i}}^{n} w_{j i} \times X_{j}^{\kappa}\right) \\
\text { Modified Kosko : } X_{i}^{(\kappa+1)}=f\left(X_{i}(t)+\sum_{j=1}^{n} X_{j}(t) \cdot w_{j i}\right. \\
\text { Rescale : } X_{i}^{(\kappa+1)}=f\left(\left(2 \times X_{i}^{\kappa}-1\right)+\sum_{j=1, j \neq i}^{n} w_{j i} \times\left(2 \times X_{j}^{\kappa}-1\right)\right.
\end{array}\right)
$$

where $X_{i}^{(\kappa+1)}$ is the value of concept $C_{i}$ at simulation step $\kappa+1, X_{j}^{\kappa}$ is the value of concept $C_{j}$ at the simulation step $\kappa, w_{i j}$ is the weight of the interconnection between concept $C_{i}$ and concept $C_{j}$, $\kappa$ (Greek letter Kappa) is the interaction index and every simulation step, and $\mathrm{f}(\cdot)$ is the threshold (activation) function. The function is selected to retain the values within the range $[0,1]$ or $[-1,1]$. Equation (2) is the original Kosko activation function (1) that takes past values (or history) of a concept into account [38]. Generally, there are four most used transformation functions (4)-(7): (a) bivalent, (b) trivalent, (c) sigmoid, and (d) hyperbolic tangent.

$$
\begin{gathered}
\text { Bivalent : } f(x)= \begin{cases}1, & x<0 \\
0, & x \geq 0\end{cases} \\
\text { Trivalent : } f(x)=\left\{\begin{array}{c}
1, x>0 \\
0, x=0 \\
-1, x<0
\end{array}\right. \\
\text { Sigmoid (linear) : } f(x)=\frac{1}{1+e^{-\lambda x}} \\
\text { Hyperbolic tan gent : } f(x)=\tanh (\lambda x)
\end{gathered}
$$

where $\lambda$ is a real positive number $(\lambda>0)$, which determines the steepness of the continuous function $f$ and $\mathrm{x}$ is the value $X_{i}^{\kappa}$ on the equilibrium point. At each step, the value $X_{i}$ of a concept is influenced by the values of concepts connected to it and it is updated according to the inference rule. This process continues until the system converges, which indicates that the difference between two subsequent value of the outputs values must be equal or lower to $\varepsilon$ (epsilon, $\varepsilon=0.001$ ). 


\section{PSE in Brazil}

\subsection{Problem Statement}

Environmental degradation caused by deforestation, gas emission, and environmental pollution has caused countries to rethink their electric systems. As a solution to the problems caused by the unsustainable exploration of fossil fuels, renewable energies have become the focus of attention of a broad range of agents. However, in Brazil, unlike other countries, the investment in photovoltaic solar energy was driven by different reasons, such the increase in the cost of energy produced in thermoelectric plants and the emission of greenhouse gases by burning of fossil fuels [39,40].

Among other solutions, PSE shows up as a viable and necessary source of electrical energy. Given that it is located mostly in the intertropical region and has excellent potential for solar energy utilization throughout the year, the Brazilian solar radiation is higher than the European for almost its entire territory [41]. Based on Renewable Energy Country Attractiveness Index [42], Brazil is eighth in the raking of attractiveness when speaking of photovoltaic solar energy. In 2014, Brazil had its total installed to power up to $15 \mathrm{MW}$, and in 2015, the same number surpassed $32 \mathrm{MW}$. Statistics of the Mines and Energy Ministry [43] indicated that by 2018 Brazil should be between the 20 countries with the most prominent generation of solar energy.

On the other hand, the high cost of acquisition of photovoltaic and their low conversion efficiency from solar irradiation to electrical energy are the main impediments to the large-scale diffusion of these systems $[44,45]$. As a solution, the government can understand the dynamic of PSE development from other countries and propose policies that improve the use of solar energy in an urban environment [46]. Given that the future of the PES depends on several issues, it needs to be planned and controlled. For this purpose, scenario planning is a fundamental tool [47].

\subsection{Model Development}

In order to provide a quasi-quantitative model for scenario planning, regarding the studied problem of PSE development in Brazil, the FCM development process was conducted in six steps. Figure 1 offers a visual representation of these steps for better understanding of the procedure and for the convenience of the readers.

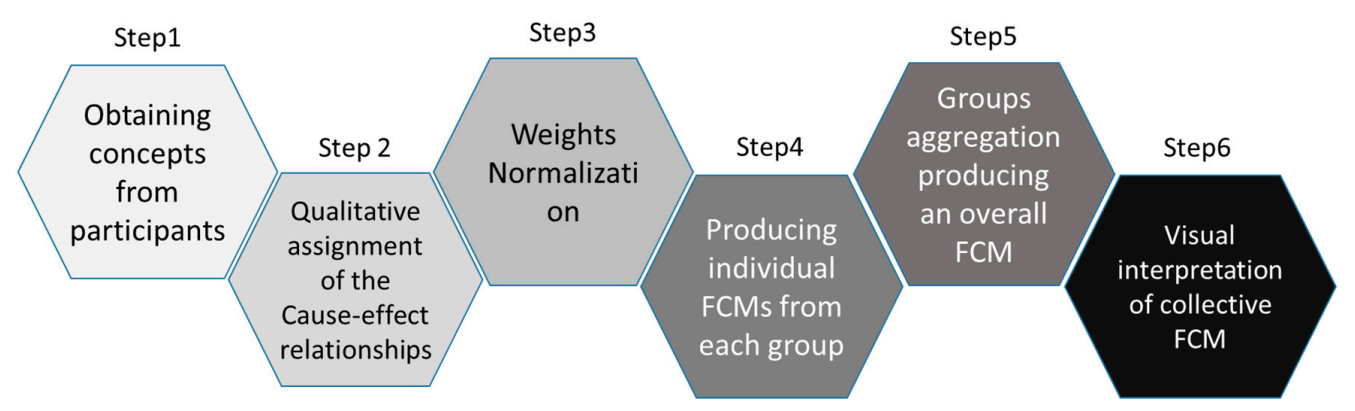

Figure 1. The steps of FCM development process.

Step 1: Obtaining concepts from participants.

The first step deals with the determination of the most essential independent variables that define the examined problem and affect the dependent variable. Participants are asked to determine the concepts of the system but only the most important in order to avoid designing a system with a vast number of variables that would be difficult to study.

Step 2: Qualitative assignment of cause-effect relationships between concepts.

In the second step, participants are asked to assign values on the scale of 1-10 and to determine whether there is a positive or negative cause-effect relationship for the weighted interconnections 
among the depended and most significant variables that constitute the FCM model. Ten (10) denotes the highest strength and one (1) the lowest. The sign + (plus) denotes a positive influence, whereas the sign - (minus) denotes a negative influence that one node has to another.

Step 3: Weights Normalization (coding into an adjacency matrix).

Weights given to each link were then normalized between 0 and 1 (as described in Table 1), considering positive and negative values for coding into the adjacency matrix [48]. So, we substitute the qualitative values assigned by the stakeholders for expressing the degree of influence with the corresponding quantitative values, in order to define the weight matrix of each stakeholder, as presented in Table 1. For example, the qualitative value 10 (that denotes the highest strength) is substituted by the quantitative weight value 1.

Table 1. Normalizing Qualitative (linguistic) values to Quantitative values for the weighted interconnections.

\begin{tabular}{lclc}
\hline $\begin{array}{l}\text { Qualitative Opinion } \\
\text { (Linguistic Values) }\end{array}$ & $\begin{array}{c}\text { Weight Value } \\
\text { (Quantitative) }\end{array}$ & $\begin{array}{c}\text { Qualitative Opinion } \\
\text { (Linguistic Values) }\end{array}$ & $\begin{array}{c}\text { Weight Value } \\
\text { (Quantitative) }\end{array}$ \\
\hline 1 - Extremely low & 0.1 & 6 - Medium high & 0.6 \\
2 - Very low & 0.2 & 7 - High & 0.7 \\
3 - Low & 0.3 & 8 - Very High & 0.8 \\
4 - Medium low & 0.4 & 9 - Extremely high & 0.9 \\
5 - Medium & 0.5 & 10 - Highest strength & 1 \\
\hline
\end{tabular}

Step 4: Producing individual FCMs from each group.

In this step, every group of the participants was asked to construct an individual FCM by defining the primary variables and determining the weights values of all causal relationships. This process also includes the identification of the decision concept, which is a dependent variable for the problem under investigation. As we aim to analyze the Brazilian Solar Photovoltaic Energy Sector, the dependent variable was set to be the "Development of PSE in Brazil". The procedure that was followed, is described below in detail, as the authors want to highlight the importance of all the steps taken for the success of this study.

Step 5: Groups Aggregation producing an Overall FCM.

In this step, all individually coded cognitive maps from the three groups were aggregated and an overall group FCM (Collective-FCM) was produced that includes all the concepts from all individual cognitive maps. This collective FCM represents the perception of all the stakeholders and is enriched with the knowledge of all stakeholders involved.

Step 6: Visualization of collective FCM.

After the aggregation process, that was based on the weighted average method, the Collective-FCM was analyzed using the FCMWizard software tool (version 1.0, E.I. Papageorgiou, Larissa, Greece). Since the tool includes modelling and visualization capabilities, a visual representation of the condensed FCM model was created by FCMWizard, which specifically illustrates the concepts and all the connections between them. The graphical representation of the collective FCM is presented in Section 4.1, where an overview of the FCMWizard tool is presented.

Following the steps above, the authors carried out the project with the help of researchers of the University of São Paulo (USP) and University of Brasília (UNB) specialized in the solar photovoltaic energy. They along with other specialized stakeholders (such as specialists from the National Electric Energy Agency (government), the Brazilian Solar Energy Association (professionals)) were the primary sources of data and information for the development of this research.

Interviews were conducted individually or with pairs of specialists from the National Electric Energy Agency (government), the World Wildlife Fund (NGO), Brazilian Solar Energy Association 
(professionals), and researchers from the University of São Paulo and Brasília (specialists). A workshop was also carried out with a group of eight graduate students of the Institute of Energy and Environment of the University of São Paulo, IEE/USP, to consolidate the FCMs.

Specifically, a pretest was first carried out with a potential consumer with a business background, through an individual interview, during which the dynamics of FCMs and the proposed method were explained. The respondent had trouble defining the primary variables (concepts) and establishing the exact weights (from -1 to 1 ) of the causal relations. After proper guidance and following the contents of Table 1, in the end, he managed to develop a potential FCM.

The second FCM was constructed after interviewing a specialist in SPE from the University of Brasília (UNB). He responded with great enthusiasm and a consensus was reached for 12 interrelated concepts, establishing at the same time the causal relations and respective weights.

In the next FCM, the proposed method was investigated with the help of a group of SPE specialists from IEE/USP. In a workshop with eight participants, the dynamics of FCMs and the proposed method were explained. These specialists identified 13 concepts and established their connections and weights. In this type of approach (workshop), the most prominent advantage came from the debate among the participants. Instead of creating individual FCMs, the authors suggested a collaborative process for scenario planning where the participants cooperated to produce a more productive and accurate knowledge in the form of a consolidated FCM. The weight value for each interconnection is calculated as the average of all values that each participant gave for the corresponding interconnection, taking into consideration Table 1. However, the FCM achieved by the group of specialists from USP, presented in Figure 2, was not a significant improvement regarding complexity and robustness in comparison with the others.

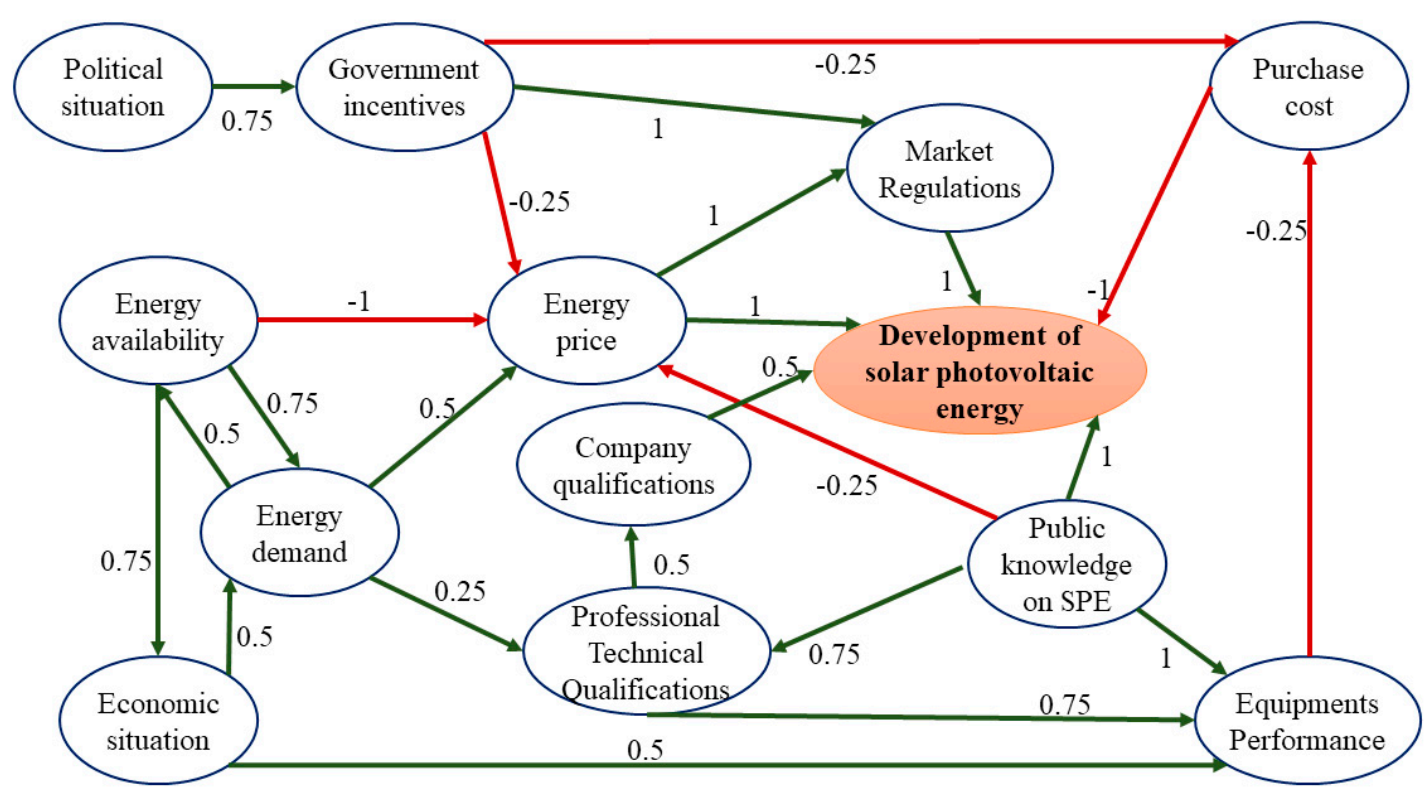

Figure 2. FCM from a group of the specialist of IEE/USP (average weight values).

The FCMs elaborated from the information of the specialists, and stakeholders were integrated into a single FCM. Table 2 presents the list of the concepts contained in this collective FCM, with a short description of them. They identified 29 concepts in total and established the connections and weights among these concepts. Also, they determined the 10 most central concepts (concepts in bold in Table 2) in terms of significance in the decision making process through scenario analysis. Moreover, the weights of the connections were equal to the average of the weights established by the specialists and stakeholders. 
Table 2. List of concepts integrating the collective FCM.

\begin{tabular}{|c|c|c|}
\hline Concept & ID & Description \\
\hline $\begin{array}{l}\text { Development of solar } \\
\text { photovoltaic energy }\end{array}$ & $\mathrm{C} 1$ & Possible evolution of the Photovoltaic Solar Energy Sector in Brazil \\
\hline Potential generating jobs & $\mathrm{C} 2$ & Refers to the capacity to create employment. \\
\hline Market competition & $\mathrm{C} 3$ & \\
\hline Public knowledge of SPE & $\mathrm{C} 4$ & $\begin{array}{l}\text { Society's understanding and awareness of the functioning and role of } \\
\text { PS energy in energy systems and everyday use. }\end{array}$ \\
\hline $\begin{array}{l}\text { Public opinion (ecological and } \\
\text { social consciousness) }\end{array}$ & C5 & Public awareness regarding the importance of environmental protection \\
\hline Purchase cost & C6 & $\begin{array}{l}\text { The price of energy product or services that are available for purchase } \\
\text { by suppliers or consumers. }\end{array}$ \\
\hline Maintenance costs & $\mathrm{C} 7$ & The expenses incurred to keep an item in good condition or good working order \\
\hline Energy demand & $\mathrm{C} 8$ & The quantity of energy that consumers wish to acquire for a set price in a market. \\
\hline Energy availability & C9 & $\begin{array}{l}\text { The amount of energy from various energy recourses that is } \\
\text { available for consumption }\end{array}$ \\
\hline Decentralized energy creation & $\mathrm{C} 10$ & $\begin{array}{l}\text { Energy production facilities closer to the site of energy consumption that allow } \\
\text { for more optimal use of renewable energy }\end{array}$ \\
\hline Government incentives & C11 & $\begin{array}{l}\text { They are benefits granted by governments to foster the progress of the sector (tax } \\
\text { exemptions, financing lines, demand creation). }\end{array}$ \\
\hline Private sector involvement & $\mathrm{C12}$ & The participation of the private sector in energy projects of the government. \\
\hline Geographical location & $\mathrm{C} 13$ & $\begin{array}{l}\text { Geographic location refers to a position of the country on Earth. Defined by } \\
\text { longitude and latitude. }\end{array}$ \\
\hline Energy dependence concerns & C14 & Energy source dependence. Need to diversify the energy matrix. \\
\hline $\begin{array}{l}\text { ABNT (Brazilian Technical } \\
\text { Standards) }\end{array}$ & $\mathrm{C} 15$ & $\begin{array}{l}\text { A private non-profit organization which is responsible for technical standards in } \\
\text { Brazil, and intends to promote technological development in the country }\end{array}$ \\
\hline Payback Period & C16 & $\begin{array}{l}\text { The length of time required for an investment to recover its initial outlay in terms } \\
\text { of profits or savings. }\end{array}$ \\
\hline Environmental pollution & $\mathrm{C} 17$ & $\begin{array}{l}\text { The addition of any substance or any form of energy to the environment at a rate } \\
\text { faster than it can be dispersed, diluted or decomposed. }\end{array}$ \\
\hline Energy price & C18 & The value of the energy expressed in monetary terms. \\
\hline National production equipment & $\mathrm{C} 19$ & $\begin{array}{l}\text { Production equipment that belongs to a country and its purpose is to produce } \\
\text { goods of a wanted quality when provided with production resources of a } \\
\text { required quality }\end{array}$ \\
\hline Equipment performance & $\mathrm{C} 20$ & Effectiveness of output of a given piece of equipment. \\
\hline Companies' qualifications & $\mathrm{C} 21$ & Certain requirements or certificates for specific occupational needs. \\
\hline $\begin{array}{l}\text { Professional technical } \\
\text { qualifications }\end{array}$ & $\mathrm{C} 22$ & $\begin{array}{l}\text { Associated with how excellent the professionals' skills are. It means the } \\
\text { attributes and characteristics of a worker. }\end{array}$ \\
\hline Availability of alternative energies & $\mathrm{C} 23$ & $\begin{array}{l}\text { The amount of energy from alternative energy recourses that is } \\
\text { available for consumption }\end{array}$ \\
\hline Market regulations & $\mathrm{C} 24$ & $\begin{array}{l}\text { Government regulations to ensure that markets function } \\
\text { effectively and efficiently. }\end{array}$ \\
\hline Economic situation & $\mathrm{C} 25$ & $\begin{array}{l}\text { It is the capacity of an economy to produce goods and services. In Brazil, the } \\
\text { most common proxy used is a Gross domestic product (GDP). }\end{array}$ \\
\hline Global treaties & $\mathrm{C} 26$ & $\begin{array}{l}\text { A formal agreement between two or more independent governments that impact } \\
\text { the energy sector (Kyoto Protocol, Montreal Protocol). }\end{array}$ \\
\hline Taxation & $\mathrm{C} 27$ & $\begin{array}{l}\text { Taxes account for a significant share of the final prices consumers pay for energy } \\
\text { and can have a significant impact on consumption and investment patterns. }\end{array}$ \\
\hline Political situation & $\mathrm{C} 28$ & The way power is achieved and used in a country \\
\hline Technological maturity & $\mathrm{C} 29$ & Technological progress or growth \\
\hline
\end{tabular}

In this context, a 29-nodes FCM model was produced from the experts/stakeholders and its adjacency matrix (see Figure 3) was created accordingly, including the causal relationships between the concepts and their weight. 


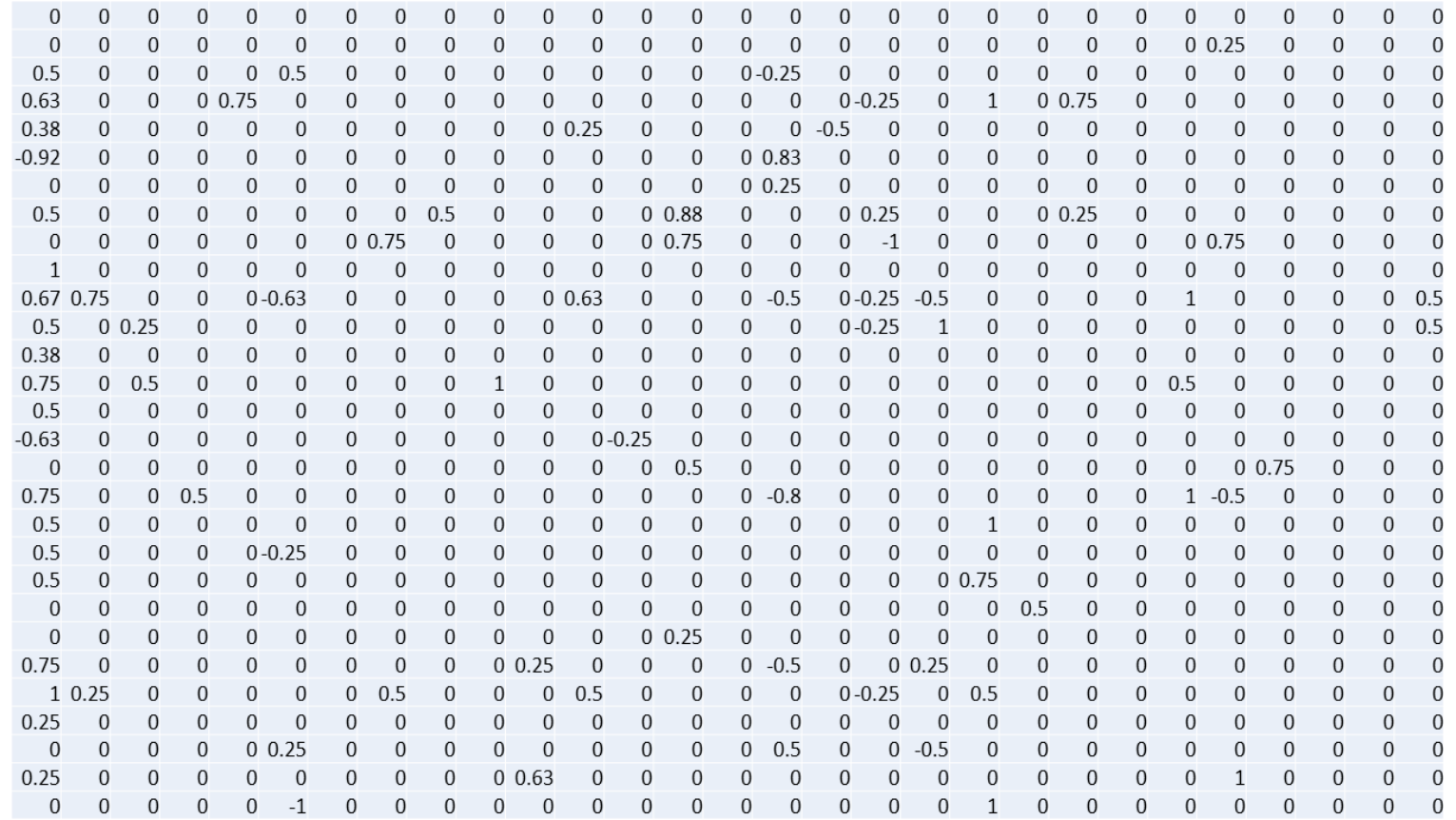

Figure 3. Adjacency matrix.

\section{Overview of the FCMwizard Tool}

This section provides an overview of the FCMWizard tool in which the functionalities of this software are presented. In order to illustrate the capabilities of this tool on modelling and simulating a dynamic and complex system, the authors use the case study of the renewable energy sector of Brazil. Among the functionalities that site on the main menu (see Figure 4), there are three main modes for constructing an FCM, namely: (i) Expert mode wherein experts and/or stakeholders can construct manually a FCM for a real problem; (ii) Data-based Learning mode wherein the FCM model is constructed automatically using given data; and (iii) Merge mode, where different individual FCMs can be combined to provide an augmented and collective FCM model in order to generate aggregated system complexities.

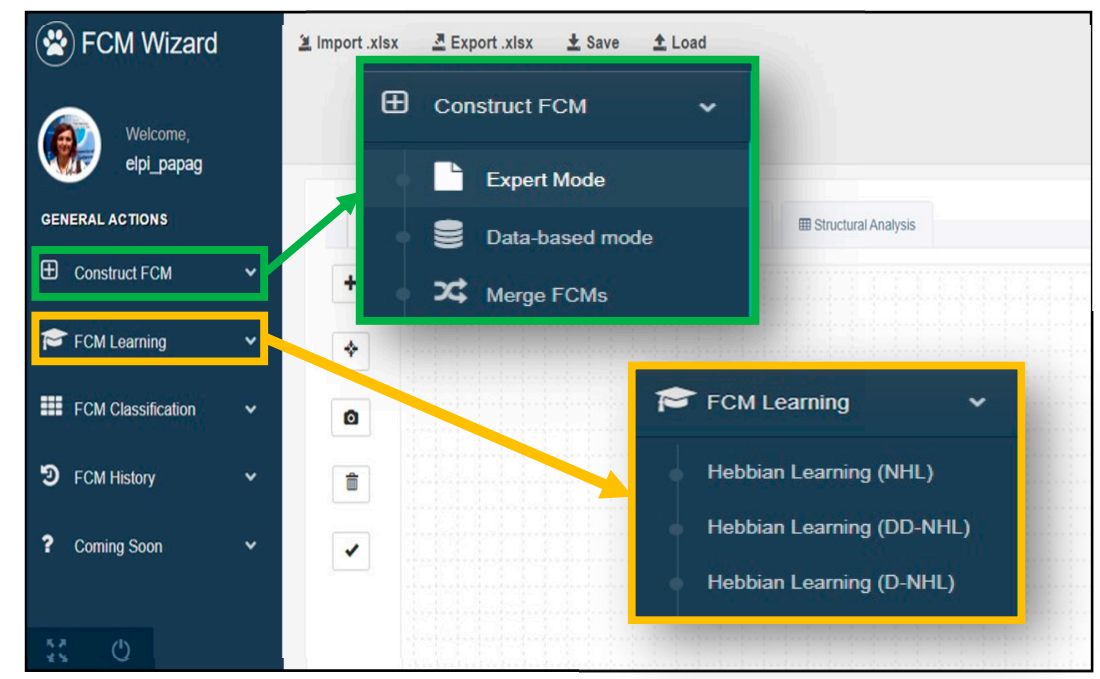

Figure 4. FCMWizard Main menu, with FCM construction and FCM Learning modes.

FCMWizard offers a Main menu with 2 main functionalities: FCM construction and FCM Learning. FCM Learning includes three learning modes (see Figure 4): (i) Hebbian Learning (NHL): weights are 
fine-tuned by data assuming that all the concepts are synchronously triggered at each iteration and they synchronously change their values. Constraints on concepts and weights can be considered for updating weighted connections. (ii) Data-driven Hebbian Learning (DD-NHL): an extended NHL method through historical data for the input concepts to fine-tune weights, and (iii) Differential Hebbian Learning (D-NHL): This algorithm correlates the changes in the concepts to modify their weights [2].

Next, the authors will illustrate how the FCM Wizard tool can be used to construct an FCM model and visualize its results for the given problem of PSE in Brazil. Moreover, the structural analysis, the Hebbian-based Learning and the scenario analysis will be further described, along with relevant figures and tables, produced by the tool.

\subsection{Expert-Based Construction/Modelling}

Without a deeper knowledge of the mathematical foundations of the methodology and regardless of the type of application domain, users can create new concepts and causal relationships between them, using influence weights, to design a new model. The "Expert Mode" under the main menu "Construct FCM", provides users with the ability to easily design an FCM model by adding new nodes when the "+" button in the "Model Design" tab is selected. Then, new directed lines can be drawn representing the causal relationships between nodes, in which a green direct relationship denotes a positive weight and a red inverse relationship denotes a negative weight.

So, the FCM model that was designed by the stakeholders can be easily constructed, as illustrated in Figure 5, using the FCMWizard tool, following the process described above. This consensus FCM model comprises the concepts in the form of nodes $(\mathrm{C} 1, \mathrm{C} 2, \ldots, \mathrm{C} 29)$ and directed lines (green or red) with the corresponding weight (positive or negative). Moreover, this FCM model can be directly designed by the FCMWizard, after properly importing the adjacency matrix (see Figure 3 ) in the tool, as provided by the Stakeholders. The weight matrix, as illustrated in the tab "weight matrix" of the tool, is presented in Figure 6. Each number of this weight matrix represents the causal relationship between the concepts that are sited in the corresponding row and column of this matrix.

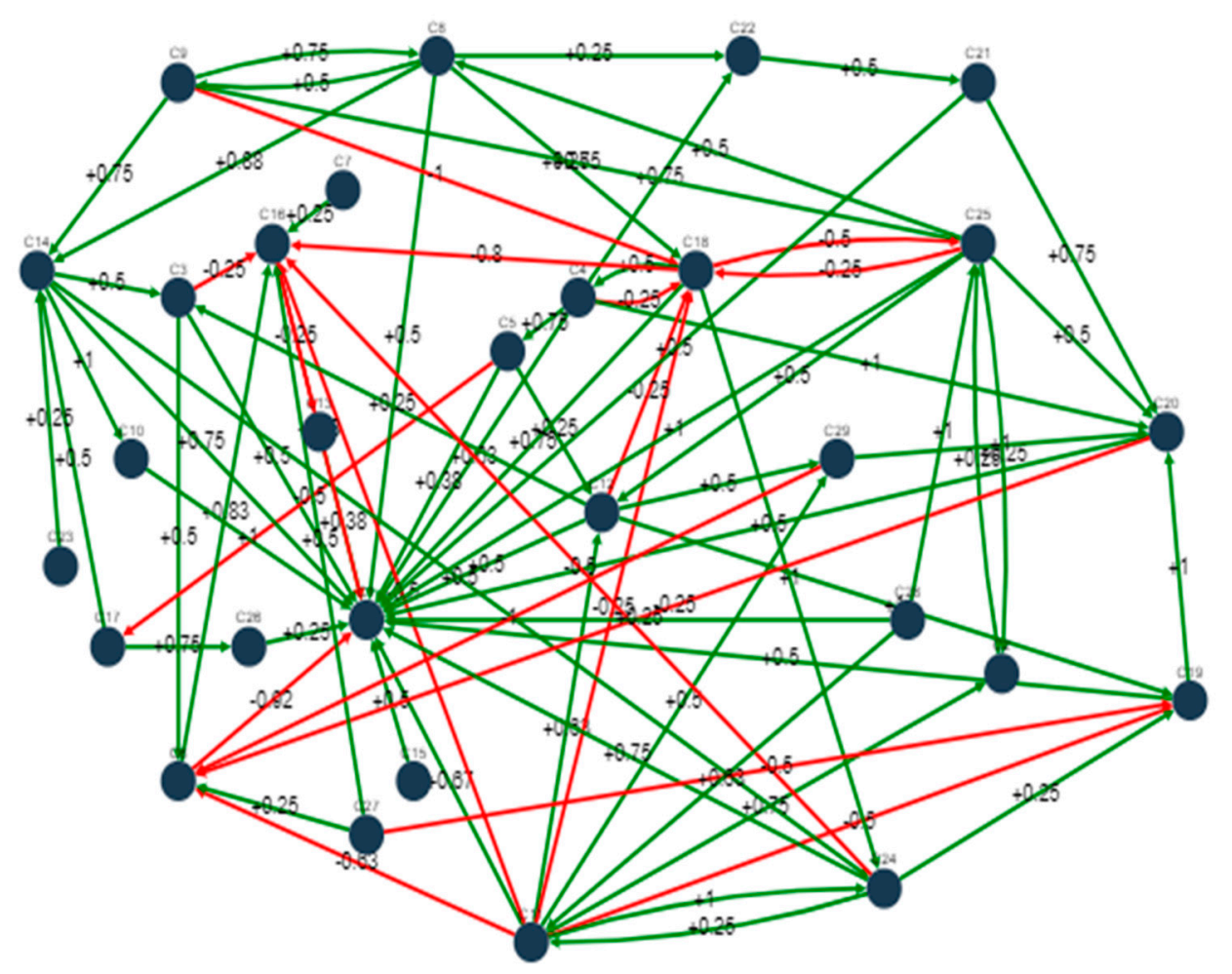

Figure 5. Consensus FCM model for PSE in Brazil designed in FCMwizard tool. 


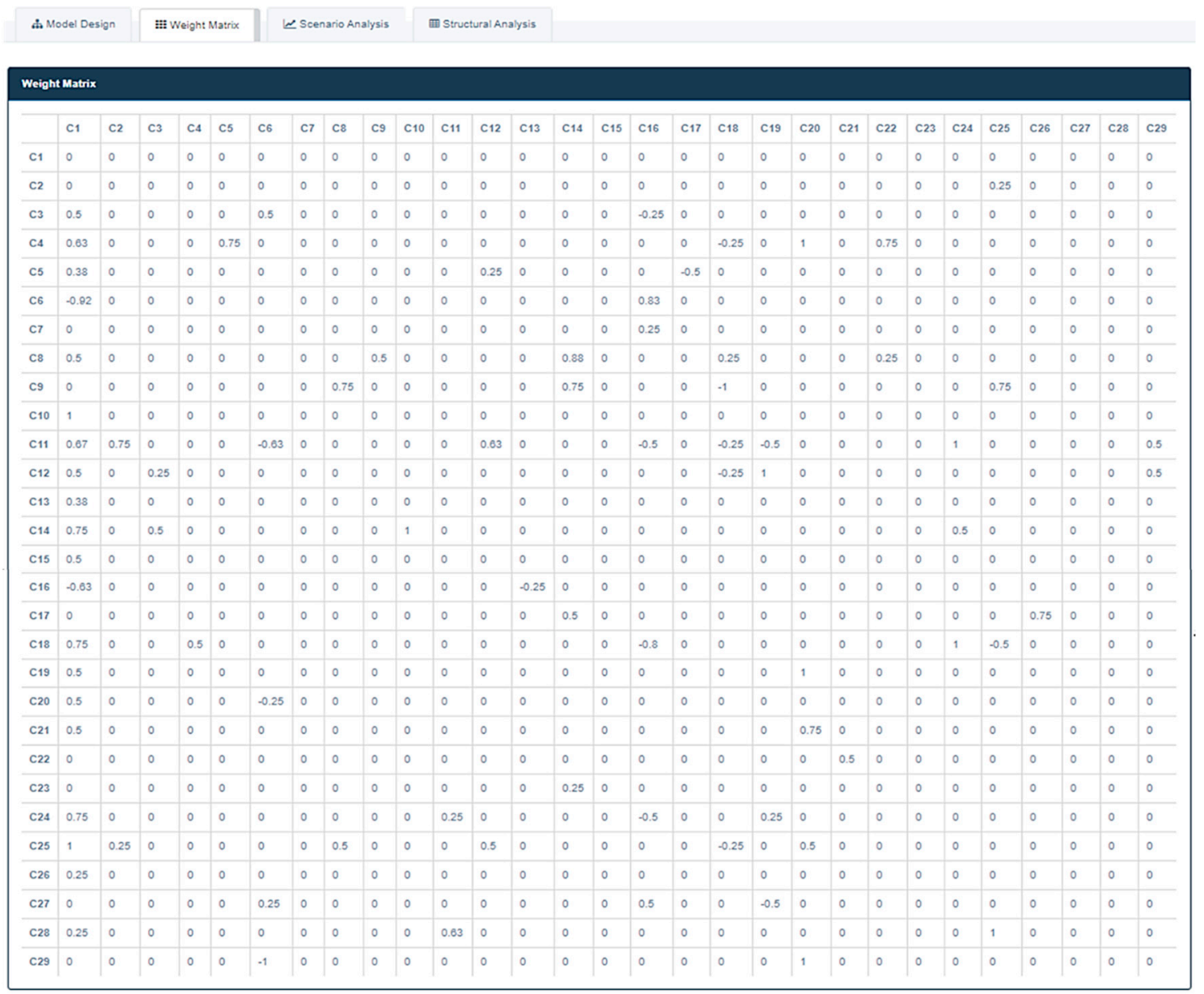

Figure 6. Screenshot of weight matrix of the final consensus FCM model produced in FCMWizard.

\subsection{Structural Analysis}

This software module encapsulates the ability to calculate various graph theory indices like the total number of concepts, number of connections, connection-to-concept ratio, outdegree, indegree, type of variables (receiver, transmitter or ordinary), degree centrality, betweenness centrality, closeness centrality, complexity ratio, density, and hierarchy index [33,49]. In Figure 7, a snapshot of the first eight concepts' graph indices is illustrated. Centrality is considered a significant index, so that a concept with a high degree of centrality has an important role in the cognitive map $[8,49]$. Centrality is calculated by the sum of the corresponding absolute indegree and outdegree causal weights [50]. Table 3 gathers the two most important indices of centrality (Degree and Betweenness) for all 29 concepts, as calculated by the tool. As observed from Figure 7 and Table 3, the concepts C1, C4, C6, C8, C11, C14, C16, C18, $\mathrm{C} 24$, and C25 present a higher degree of centrality than the rest of the concepts, so they can have a significant role on the examined energy system.

Complexity, density and hierarchy index too, are among significant structural indices for analyzing the graphical structure of FCMs.

From the constructed FCM model (Figure 5), it emerges that concepts with the most substantial number of connections are: Public knowledge on SPE (C4), Public opinion (C5), Energy demand (C8), Government incentives (C11), Private sector involvement (C12), Environmental pollution (C17), Energy price (C18), and Economic situation (C25). These key concepts are also directly and strongly connected to the objective concept C1 (development of solar photovoltaic energy). Hence, in terms of their degree of centrality and connectedness (see Figure 7 and Table 3), concepts C4, C5, C11, C17, 
and C18 were chosen by the researchers to become the base of the scenarios since they can strongly affect the behavior of the system.

\begin{tabular}{|c|c|c|c|c|c|c|c|c|}
\hline \multicolumn{9}{|c|}{ (Nodes) Graph Indices } \\
\hline & c1 & c2 & c3 & $\mathrm{C} 4$ & C5 & c6 & c7 & c8 \\
\hline Outdegree & 0.0 & 0.3 & 1.3 & 3.4 & 1.1 & 1.8 & 0.3 & 2.4 \\
\hline Indegree & 11.9 & 1.0 & 0.8 & 0.5 & 0.8 & 2.6 & 0.0 & 1.3 \\
\hline туре & Receiver & Ordinary & Ordinary & Ordinary & Ordinary & Ordinary & Transmitter & Ordinary \\
\hline $\begin{array}{l}\text { Degree } \\
\text { Centrality }\end{array}$ & 11.9 & 1.3 & 2.0 & 3.9 & 1.9 & 4.4 & 0.3 & 3.6 \\
\hline $\begin{array}{l}\text { Betweenness } \\
\text { Centrality }\end{array}$ & 441.4225108225107 & 0.4 & 13.573809523809523 & 23.814285714285706 & 20.933766233766224 & 28.926190476190474 & 0 & 35.479437229437224 \\
\hline $\begin{array}{l}\text { Closeness } \\
\text { Centrality }\end{array}$ & 24 & 12.5 & 16.166666666666664 & 15.833333333333334 & 15.166666666666668 & 16.833333333333336 & 11.083333333333334 & 16.5 \\
\hline \multicolumn{9}{|c|}{ (Graph) Graph Indices } \\
\hline \multicolumn{6}{|l|}{ Complexity } & \multicolumn{3}{|l|}{0.2000} \\
\hline \multicolumn{6}{|l|}{ Density } & \multicolumn{3}{|l|}{0.0998} \\
\hline \multicolumn{6}{|l|}{ Hierarchy Index } & \multicolumn{3}{|l|}{0.0220} \\
\hline
\end{tabular}

Figure 7. Screenshot of the "Structural Analysis" tab.

Table 3. Centrality indices (Degree and Betweenness) for all concepts, calculated in FCMWizard.

\begin{tabular}{ccccccccc}
\hline \multirow{2}{*}{ Concept } & \multicolumn{2}{c}{ Centrality } & \multicolumn{2}{c}{ Centrality } & \multicolumn{2}{c}{ Centrality } \\
\cline { 2 - 8 } & Degree & Betweenness & & Degree & Betweenness & Degree & Betweenness \\
\hline C1 & 11.9 & 441.4 & C11 & 6.3 & 63.6 & C21 & 1.8 & 11.3 \\
C2 & 1.3 & 0.4 & C12 & 3.9 & 30.8 & C22 & 1.5 & 2.6 \\
C3 & 2.0 & 13.5 & C13 & 0.6 & 0 & C23 & 0.3 & 0 \\
C4 & 3.9 & 23.8 & C14 & 5.1 & 125.0 & C24 & 4.3 & 15.3 \\
C5 & 1.9 & 20.9 & C15 & 0.5 & 0 & C25 & 5.5 & 49.7 \\
C6 & 4.4 & 28.9 & C16 & 4.5 & 106.9 & C26 & 1.0 & 7.3 \\
C7 & 0.3 & 0 & C17 & 1.8 & 5.6 & C27 & 1.3 & 1.5 \\
C8 & 3.6 & 35.4 & C18 & 5.8 & 45.5 & C28 & 1.9 & 0.4 \\
C9 & 3.8 & 3.8 & C19 & 3.8 & 21.5 & C29 & 3.0 & 1.5 \\
C10 & 2.0 & 0 & C20 & 5.0 & 29.6 & & & \\
\hline
\end{tabular}

\subsection{Scenario Analysis}

FCMWizard also provides users with the ability to perform "what-if" scenario analysis after they specified the desired parameters of the FCM model to simulate [51,52]. The initial stimulus state vector, the inference rule's type, the transfer function, its learning parameter, and the number of iterations or the convergence step need to be properly defined. Users are also offered the open/closed lock option to set and keep the value of a concept unchained throughout iterations, as being "clamped" [25].

An example of a simulation model run by the tool for the examined case is presented below and regards the investigation of the impact that concept C11-"Government incentives" has on other concepts as well as on the examined system, overall.

Before the simulation process takes place, a baseline scenario needs to be conducted, so in the next step there will be a comparison between the results of the three scenarios and those resulting from the state of the model where all the initial values of concepts are zero (baseline scenario). In Figure 8, an exemplary table with the first 20 concepts values in all iterations steps, regarding the baseline scenario, is presented, while Figure 9 depicts the corresponding graph showing the steady state of every concept comprising this FCM model. 


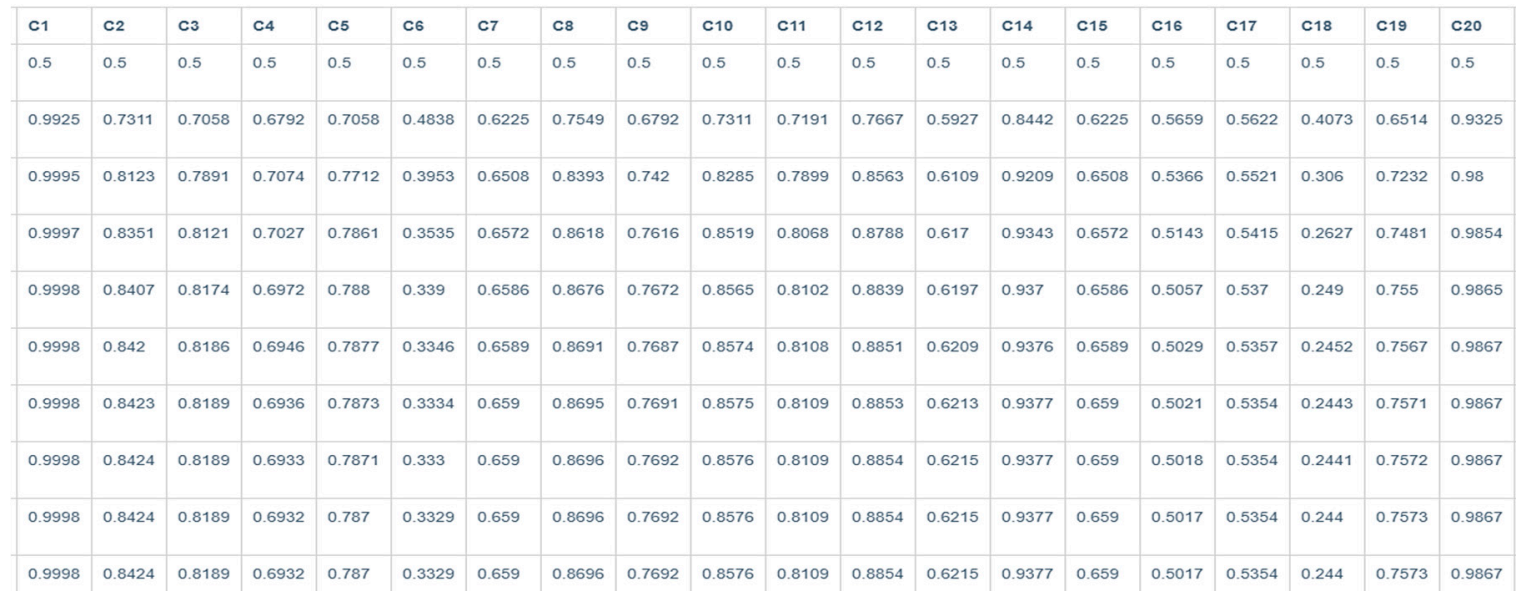

Figure 8. Screenshot of the FCM iterations steps in the baseline scenario from FCMWizard.
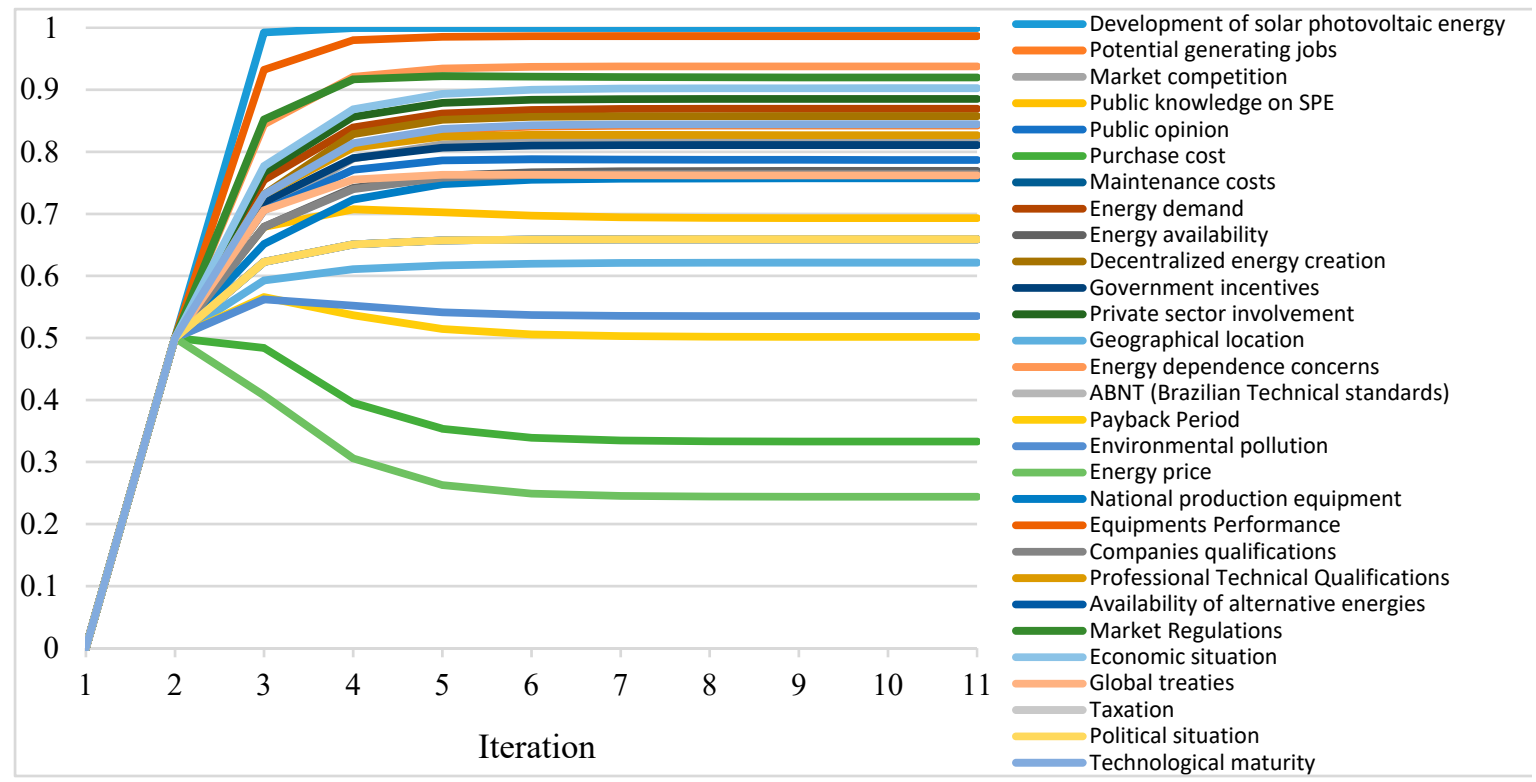

Figure 9. Screenshot of the graph regarding concepts' values in the Baseline scenario.

Let's now consider that concept "Government Incentives" (C11) is activated for the considered PSE problem, and the process of how this concept affects the other concepts needs to be investigated. For performing the scenario analysis, authors need to define a number of parameters like the inference rule, the transformation function, Lambda parameter, and either the number of iterations or the convergence step. All these simulation options and learning parameters are offered by the tool. In particular, it supports three FCM inference rules, four threshold functions, besides the possibility of customizing other parameters too [8].

In Figure 10, a screenshot of the options provided by "FCMWizard" is illustrated, regarding the parameters' configuration for the simulation process. Specifically, the initial value of the concept C11 was clamped to 1, the Modified Kosko's activation rule and the Sigmoid transformation function were selected, as well as the Lambda parameter and the convergence step were set to 1 and 0.0001 respectively.

The produced values for every concept of this scenario analysis example in the form of table and graph are depicted in the following figures (see Table 4 and Figure 11). The rest of the results are presented in Section 5.2, where the variety of functionalities and capabilities of the FCMWizard tool is further revealed. 

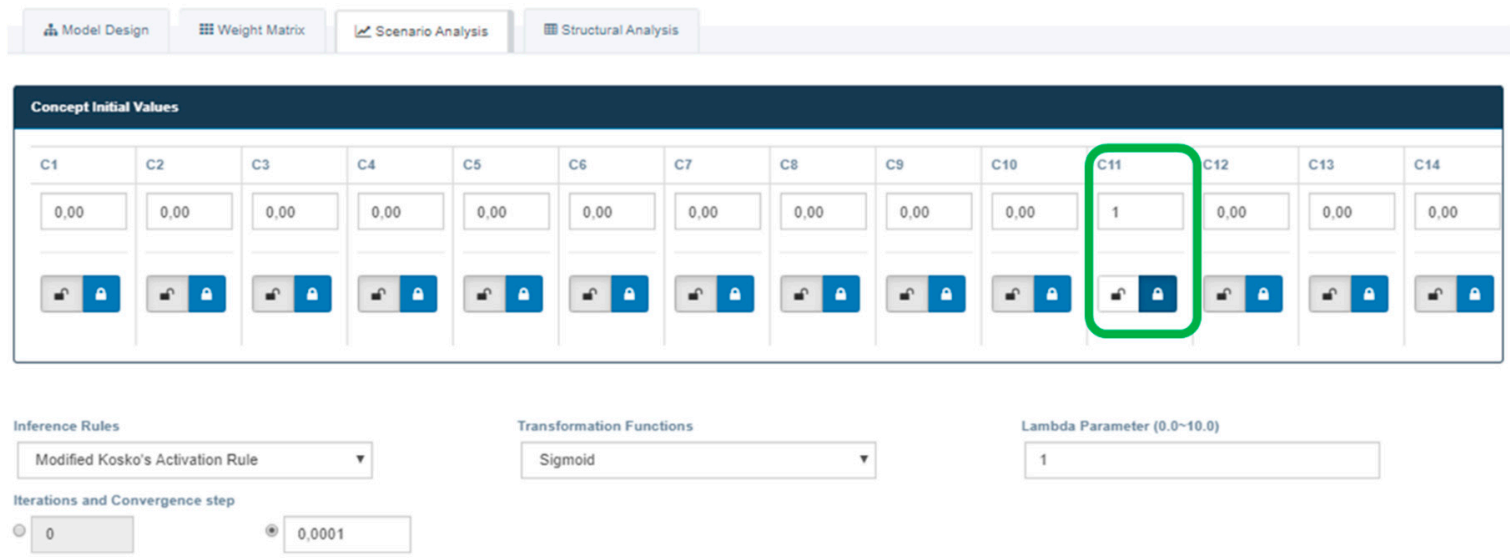
Iterations and Convergence step
0

Figure 10. Screenshot of the Scenario analysis mode by FCM Wizard.

Table 4. Table with concepts' values for each iteration, produced from FCMwizard.

\begin{tabular}{cccccccccccc}
\hline Title & C1 & C2 & C3 & C4 & C5 & C6 & C7 & C8 & C9 & C10 & C11 \\
\hline Iteration 0 & 0.661 & 0.679 & 0.5 & 0.5 & 0.5 & 0.347 & 0.5 & 0.5 & 0.5 & 0.5 & 1 \\
Iteration 1 & 0.996 & 0.825 & 0.713 & 0.672 & 0.705 & 0.341 & 0.622 & 0.759 & 0.679 & 0.731 & 1 \\
Iteration 2 & 0.999 & 0.854 & 0.793 & 0.700 & 0.770 & 0.306 & 0.650 & 0.840 & 0.742 & 0.828 & 1 \\
Iteration 3 & 0.999 & 0.861 & 0.813 & 0.698 & 0.785 & 0.297 & 0.657 & 0.862 & 0.761 & 0.851 & 1 \\
Iteration 4 & 0.999 & 0.862 & 0.818 & 0.694 & 0.787 & 0.296 & 0.658 & 0.867 & 0.767 & 0.856 & 1 \\
Iteration 5 & 0.999 & 0.862 & 0.819 & 0.692 & 0.787 & 0.296 & 0.658 & 0.869 & 0.768 & 0.857 & 1 \\
Iteration 6 & 0.999 & 0.862 & 0.819 & 0.69 & 0.787 & 0.296 & 0.659 & 0.869 & 0.769 & 0.857 & 1 \\
Iteration 7 & 0.999 & 0.862 & 0.819 & 0.691 & 0.786 & 0.296 & 0.659 & 0.869 & 0.769 & 0.857 & 1 \\
Iteration 8 & 0.999 & 0.862 & 0.819 & 0.691 & 0.786 & 0.296 & 0.659 & 0.869 & 0.769 & 0.857 & 1 \\
Iteration 9 & 0.999 & 0.862 & 0.819 & 0.691 & 0.786 & 0.296 & 0.659 & 0.869 & 0.769 & 0.857 & 1 \\
\hline
\end{tabular}

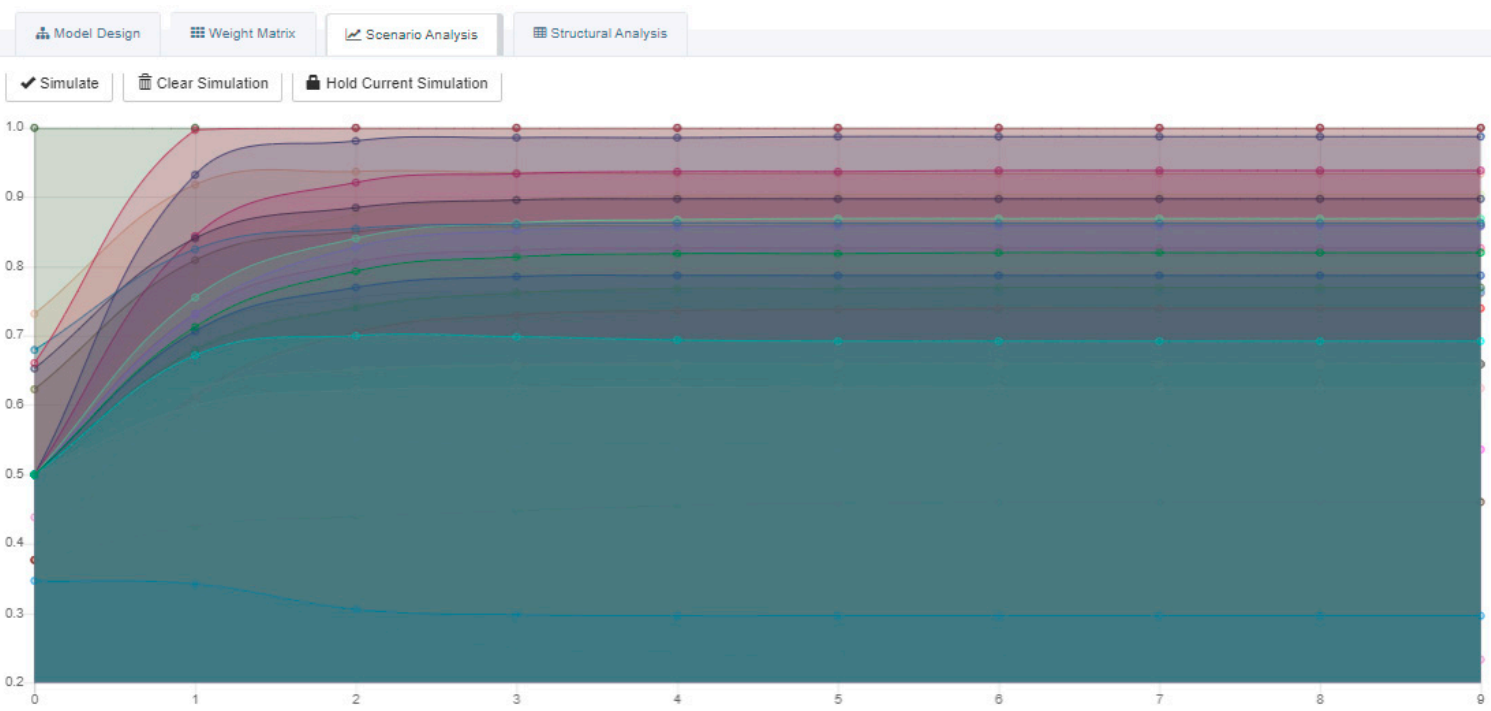

Figure 11. Graphical plot of convergence performed by FCMWizard.

Through this process, FCMWizard is proven to be a useful tool for designing FCM models and building simulations for different scenarios. It provides easy-to-use but powerful capabilities in modelling, analyzing and simulating complex systems with high uncertainty, and thus, it can be applied by policymakers for strategic decisions in various scientific domains. It should be noted that this web-based software is freely available to users upon a password request and is under continuous development. 


\section{Applying FCMWizard for Scenario Analysis}

For a deeper understanding of the examined problem, such as the concept's behavior, their relations, and the extent to which one concept has an impact on others, an FCM simulation process is needed. This study employs the FCMWizard tool to simulate and analyze the problem [25]. This process entails the multiplication of the input vector with the adjacency matrix, and in the output vector a squashing function (Equation (2)) is applied each time as a threshold function, until the system reaches a stable state.

The process of simulation is performed by "clamping" the initial value of certain key concepts each time. This outcome is compared against a baseline scenario where the system reaches the steady state. After analyzing the deviations of concepts values between the baseline steady state and the outcome of the simulation process, researchers can interpret the impact of the key concepts on the system on a quantitative basis.

\subsection{Scenario Development}

The first established approach in scenario planning was the selection of the most important concepts (called decision concepts). Among the concepts selected to construct the studied FCM model (see Table 2), the researchers identified five concepts that could well affect the behavior of the system. These concepts (C4, C5, C11, C17, and C18), given by the programme participants and implementers, were selected as they were among the concepts with the highest centrality, having both in/out-degree values, while they are strongly connected with the objective of this scenario planning, which is the development of PSE (concept C1).

For the purposes of this study, three scenarios were developed through plausible combinations of the aforementioned decision concepts. To check the behavior of the system as a whole, we tested a set of combinations in which the concepts' values were activated and clamped to one. Thus, we create three scenarios: "Instability Scenario", "Disastrous" and "Government Incentives".

The selected scenarios with their concepts are briefly presented in the following table (Table 5).

Table 5. The key concepts of each scenario.

\begin{tabular}{|c|c|c|}
\hline Scenarios & \multicolumn{2}{|c|}{ Concepts } \\
\hline Scenario 1 (S1) & C18: Energy Price & \\
\hline Scenario 2 (S2) & $\begin{array}{l}\text { C4: Public Knowledge on PSE } \\
\text { C5: Public opinion }\end{array}$ & $\begin{array}{l}\text { C11: Government Incentives } \\
\text { C17: Environmental pollution }\end{array}$ \\
\hline Scenario 3 (S3) & C11: Government Incentives & \\
\hline
\end{tabular}

- Scenario 1 (S1) examined the effects of energy price (C18) in monetary terms.

- Scenario 2 (S2) presented the effects of public knowledge on SPE (C4) in terms of general awareness of the role and significance of PSE, public opinion (C5) considering the awareness of the society about the importance of environmental protection, government incentives (C11) in terms of taxation and financial grants, along with environmental pollution (C17) in terms of energy substances affecting the environment.

- Scenario 3 (S3) highlighted the effects of government incentives (C11) in terms of taxation and other financial benefits, granted by the government.

The first scenario, namely "Instability Scenario", reflects the recent history of Brazil, in which the country is undergoing economic and political instability. The current economic crisis in Brazil began in mid-2014, and this economic crisis was accompanied and intensified by a political crisis [53]. As a result of these crises, Dilma Rousseff, president of the time, suffered impeachment in 2016 [54]. The crisis also generated unemployment, which reached its peak in 2017 [55]. In response, the price of energy has risen dramatically. Consecutively, the concept "Energy price" was chosen to be the only concept examined in this scenario and so, its value is clamped to 1. 
The "Disastrous" scenario reflects the shortage of electricity in Brazil, the blackouts, as well as some other environmental disasters, namely Mariana and Brumadinho [56]. Brazil has had to activate thermoelectric plants regularly, but this backup capacity was insufficient, and rationing had to be imposed. To avoid another "blackout crisis," the government decided to create a set of initiatives to encourage the growth of PSE, through the establishment of subsidized credit lines and tax exemptions. In 2015 and 2019, the mining dams named Brumadinho and Mariana, collapsed. Part of the demand for energy migrated to the PSE and the price of electricity provided by the government decreased. This scenario examines the impact the concepts "Public knowledge on PSE" and "Government incentives" have on the system dynamics and were accordingly activated and clamped to 1.

In the third, "Government Incentives" scenario, Government offers financial assistance to private businesses making investments through the use of economic incentives. Incentives can include tax abatements, tax revenue sharing, grants, infrastructure assistance, no or low-interest financing, free land, tax credits, and other financial resources. Thus, there seems to be more private sector involvement leading to a greater market competition, resulting in an overall energy price decrease. This could make the public feel more comfortable to consume more energy. In this scenario, the concept "Government Incentives" was clamped to 1, so the researchers can estimate through the simulation process the degree this concept affects the examined energy system.

\subsection{Scenario Analysis for PV Solar Energy Sector}

As it was reported in the "Scenario Analysis" section, the simulation process started after the baseline scenario was performed. Then, scenario analysis performed simulations for the selected three scenarios (Table 5). In this context, scenario 1 (S1) was devoted to increasing the decision concept C18- "Energy price" by "clamping" it to one. Scenario 2 (S2) studied the effects of the decision concepts C4- "Public Knowledge on PSE", C5-"Public opinion", C11-“Government Incentives" and C17- "Environmental pollution" by clamping the values of these concepts to one. In the end, Scenario 3 (S3) investigated how the increase of decision concept C11-“Government Incentives" affects the examined system, when "clamping" its values to one. The results for scenario analysis are illustrated in the following figures. The results are interpreted by comparing the relative change between this baseline scenario and the new steady state.

Figures 12-14 illustrate separately the outcomes of the three scenarios performed (S1, S2 and S3 respectively), with respect to the percentage of change (deviations from the steady state) for each concept. Thus, the authors are able to analyze and further interpret the results produced for the examined renewable energy system scenario, that will help policy makers select the right strategies in this direction. Negative values mean that the concepts have negative acceleration, whereas positive values imply that the concepts have positive acceleration. Worth mentioning is that negative change in the value of development of solar energy (C1) is regarded as a deceleration in deployment and diffusion of solar energy compared to the current state.

The end goal of the examined case study was set to be the development of the solar photovoltaic energy sector in Brazil, which is represented by the concept $\mathrm{C}$. Therefore, the scenario analysis mainly focuses on the impact that the decision concepts have on this output concept C1—“Development of solar photovoltaic energy", which is considered by the researchers as the main objective of this project. Furthermore, there is an extended discussion about how the rest of the decision concepts involved in scenario analysis, directly affect in a positive or negative way other significant concepts of the examined PSE sector. 


\subsection{Discussion of Scenario Analysis Results}

The problem of Brazilian PSE sector development is tackled with the technique of FCMs using FCMWizard as a powerful simulation environment for policy making in the renewable energy domain. The researchers have the ability to form certain scenarios with the help of energy specialists, and stakeholders form the specific domain and conduct simulations in order to observe how the examined system responds to changes of certain concepts' values. Casting a thorough look on the results presented in the figures above (Figures 12-14), certain conclusions can emerge for each scenario conducted.

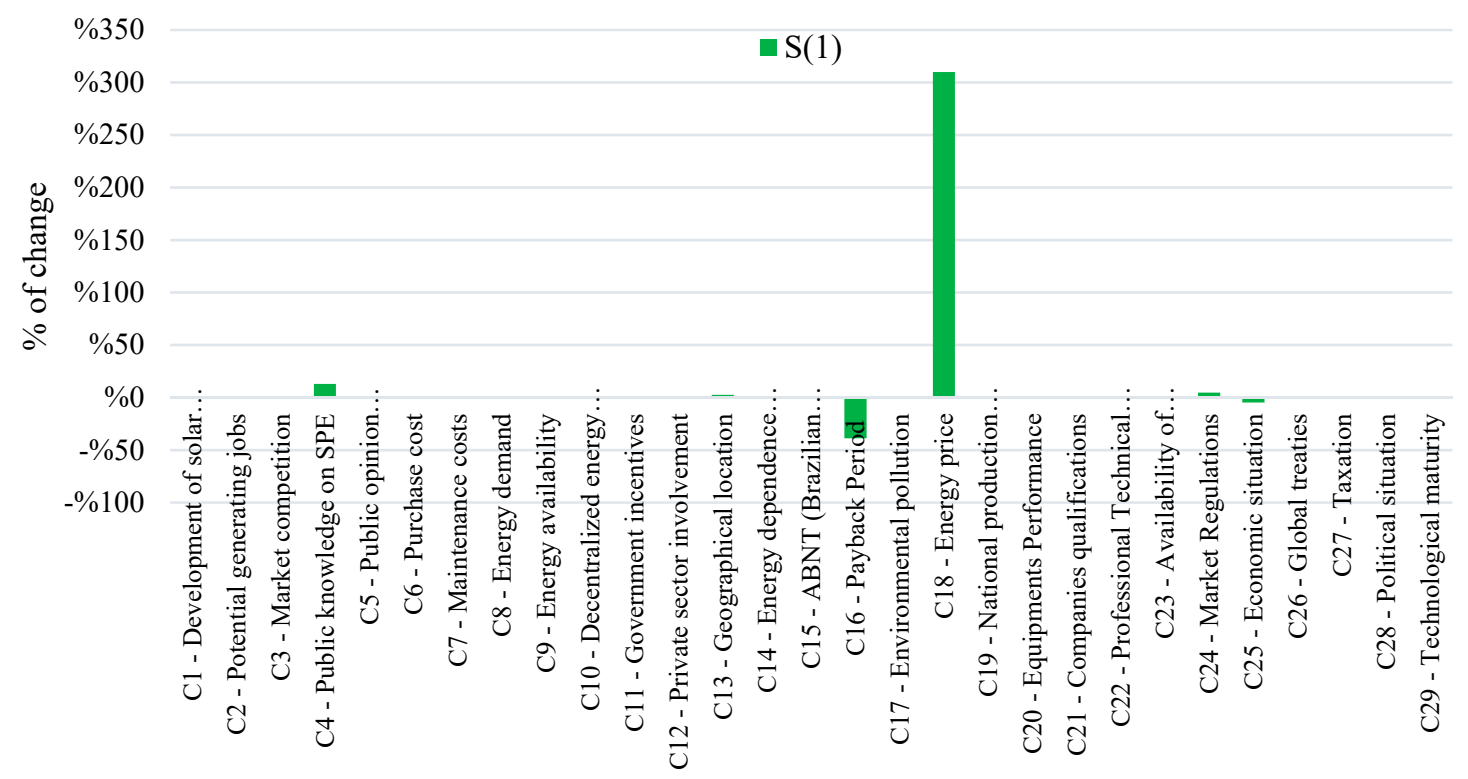

Figure 12. Percentage of change (deviation) for all key concepts when concept C18 is activated (S1).

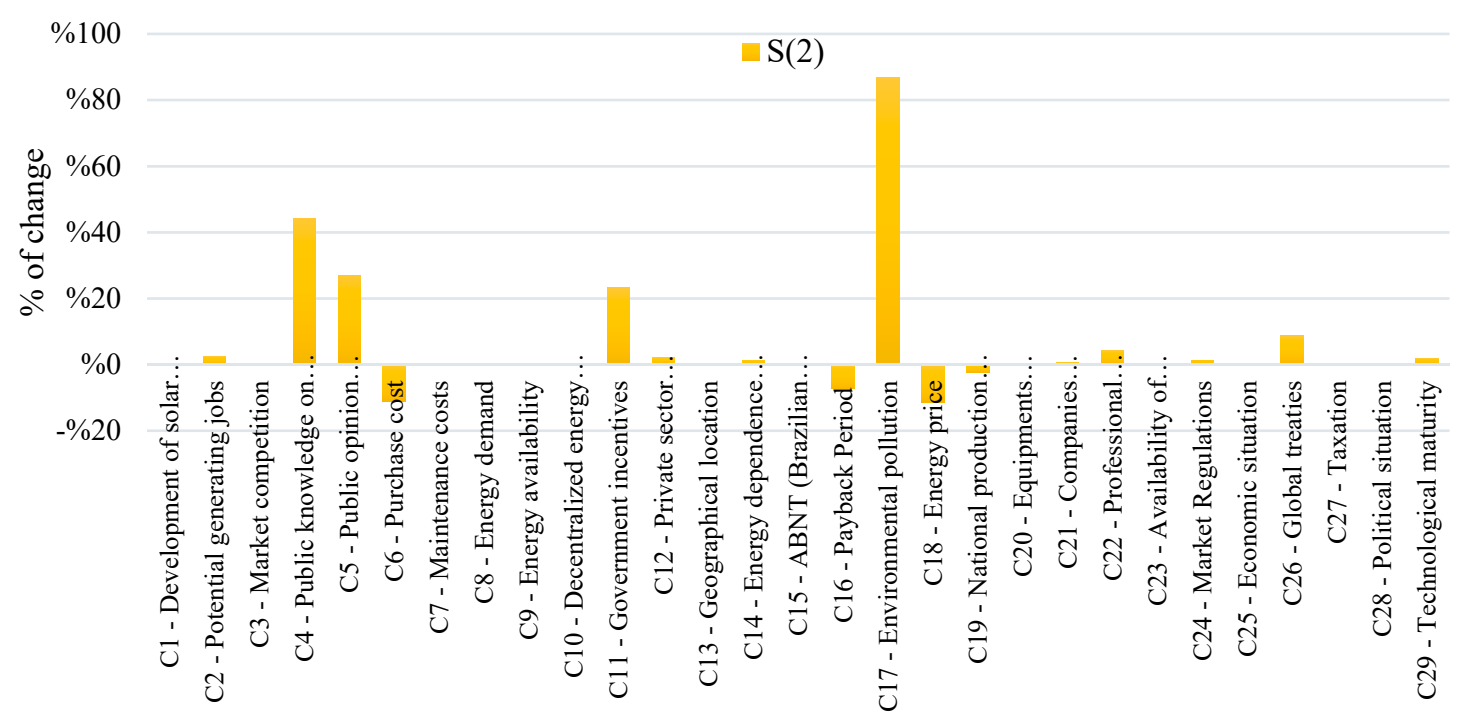

Figure 13. Percentage of change (deviation) for all key concepts when concepts $C 4, C 5, C 11$, and C17 are activated (S2). 


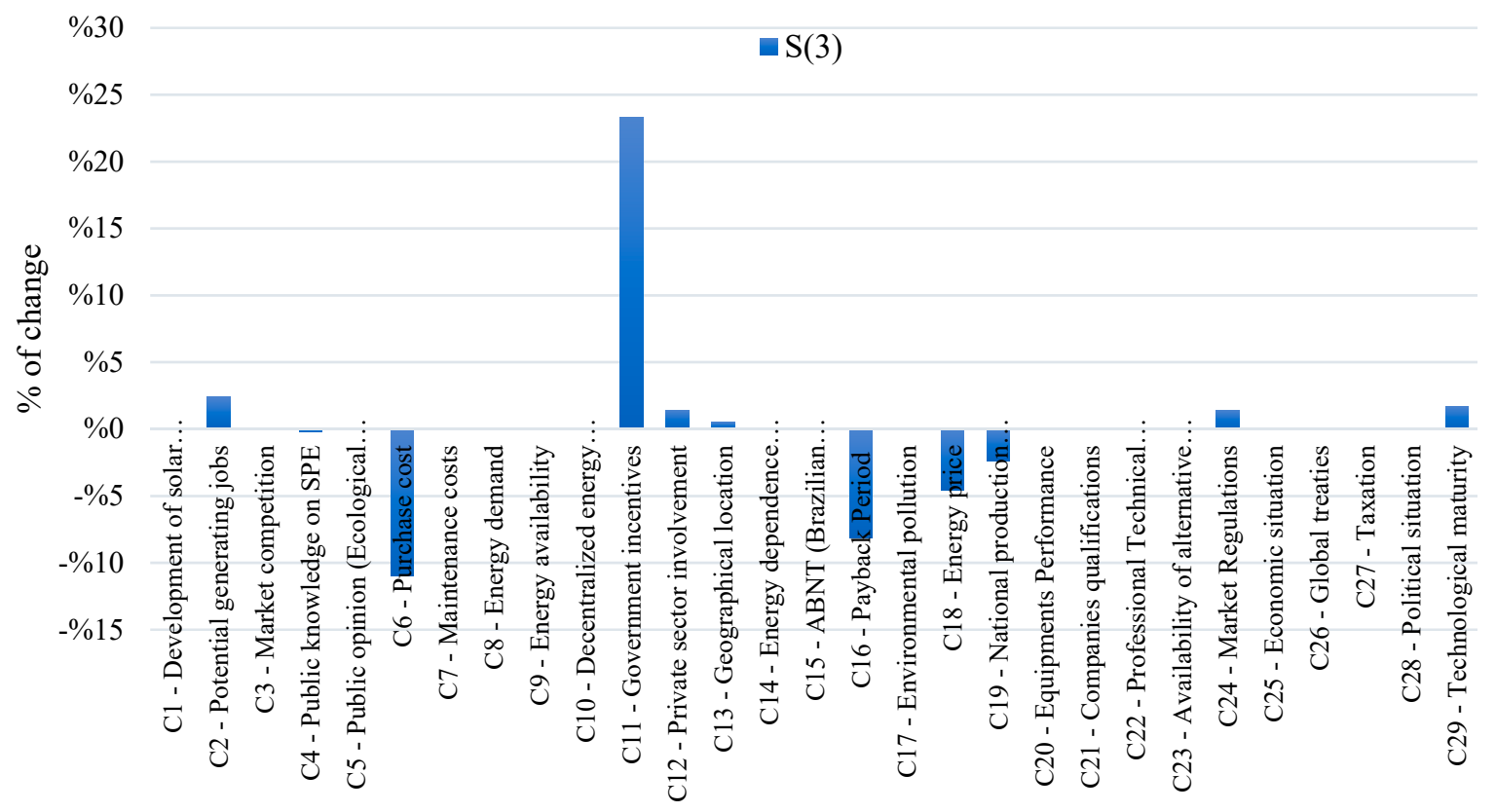

Figure 14. Percentage of change (deviation) for all key concepts when concept C11 is activated (S3).

The overall observations that were drawn from the figures above, focus on the following points:

- Considering the first conducted scenario (S1) and the "clamped" decision concept C18- "Energy price", the final values of decision concepts C1, C4, C13, C16, C24, and C25 have changed (increased or decreased) compared to those of the Baseline scenario, for the same number of iterations. Thus, it can be concluded that concept C18- "Energy price" mainly affects positively decision concepts C1, C4, C13, and C24, whereas concepts C16 and C25 are negatively affected.

- Following the same direction, the results of scenario S2 (see Figure 13) reveal that an overall increase in decision concepts C4, C5, C11, and C17 leads to a slight increase in the values of most concepts, while concepts C1, C2, C12, C22, and C25 seem to be positively affected to a greater extent. On the other hand, there is a noteworthy decrease in the final values of concepts C6, C16, C18, and C19.

- In the case of the third scenario and the clamped concept C11- "Government Incentives", the increase of its value is directly connected to an increase of the values of key concepts C2, C12, C13, C24, and C29. On the contrary, concept C11 affects inverse concepts C6, C16, C18, and C19.

- The participant concepts of Scenarios S1 and S2 have a significant positive impact on decision concept $\mathrm{C} 1$, which is the main outcome of this study, whereas Scenario 3 does not present any impact on that concept.

- When concept C11- "Government Incentives" is combined with other concepts, as participant concepts of the same scenario (S2), then it contributes to the increase of the decision concept C1 and the overall change of the examined system's state. When it performs individually, as a single concept of Scenario S3, then no impact on concept C1-“Development on PSE" and the overall system status are noticed.

Focusing on the first scenario (S1), outcomes showed that an increase in energy price led people to seek new energy sources alternatives and thus, energy demand was decreased, while public awareness of the SPE was increased, given that the payback period decreased. Furthermore, since the companies might have identified a very turbulent and disadvantageous market to exploit, a reduction in the private sector involvement is observed. Without the participation of the private sector, the purchase cost increased. 
The conclusions for the second scenario (S2) are briefly presented as follows. Since environmental pollution has sharpened people's ecological awareness and knowledge on PSE, the Brazilian government creates various initiatives and programs to foster the growth of this sector, reducing the payback time of the investment. Part of the demand for energy migrated to the PSE and the price of electricity provided by the government, decreased. The purchase cost decreased accordingly.

In response to the third scenario (S3), where government incentives are considered, economic incentives and other financial resources, given by the government, can possibly cause a significant increase in private sector involvement and greater competition in the PSE market, resulting in a bigger employment capacity. A decrease in energy price is possible and consequently, the country's own inhabitants will feel more confident to consume more energy in their daily life.

Taking into consideration the key concepts of the three conducted scenarios, it emerges that government incentives are mostly able to change the stability of Brazil's Renewable Energy system. After a critical overview of the overall results, it is unlikely the PSE sector develops much, unless there are noteworthy political and economic changes in the status of the country. Moreover, the FCM-based simulation process has shown that Brazil's PSE development is dependent on economic parameters such as the incentives given by the government and is influenced by uncertain factors like public ecological awareness. In addition, the penetration of the private sector in the PSE can affect the dynamics of the system as well as have an impact on the everyday life of Brazilian citizens.

The conducted scenarios highlighted the system's uncertainty and showed to the policy makers how they can develop effective strategies for creating a more robust system that is free from possible future instabilities. The tool settings that are offered, can help users to conduct further scenarios and try different configurations by activating different variables, individually or in a set, as well as by changing the weighted interconnections among them, in order to see how the model reacts in different circumstances.

\section{Conclusions}

This study deals with the contribution of the FCM method with the help of an efficient simulation tool called FCMWizard, which has been developed to implement/deploy certain tasks such as modeling experts' knowledge, learning and simulating FCM-based complex systems, in the participatory domain. The main contribution of this work lies in the fact that the authors provide experts and stakeholders that belong to various scientific areas, a free under request, user-friendly and flexible, as regards the number of variables and weights, tool, which can be used anytime and in any discipline or domain, without time or memory restrictions. This software that uses certain learning algorithms, offers to users the ability to easily and intuitively design a model for a particular problem, as well as perform scenario planning for making strategic decisions and policy making in a simple, user-friendly environment, without any computational cost.

The innovation in this work is based on the fact that, decision-makers can apply the Fuzzy Cognitive Map method along with the proposed software tool to model experts' or stakeholders' perceptions and further conduct different scenarios implemented by the FCMWizard tool. In this context, policy-making can be performed in various domains and with different configurations of the tool, regarding the type of inference rules, the number of variables, and the weights values or concepts' selection in the scenario planning, thus, highlighting the generic applicability and usefulness of the new tool.

To show the functionalities and examine the performance of this flexible and interactive web-based software, the authors explored a case study concerning the development of Brazil's Photovoltaic Solar energy sector and a relevant scenario analysis was performed. The main outcomes of this research will help policymakers that belong to the Renewable Energy domain, determine certain strategies for better Supply Chain Management, contributing to optimal exploitation of the PSE sector and Brazil's overall socio-economic growth. In this context, a variety of simulation options and different learning parameters were used for proper configuration of the examined system, in terms of modeling, analyzing and simulating the FCM model. In particular, three FCM inference rules and four threshold functions 
can be selected by any type of user (experts, stakeholders, policy makers or others), while a number of other useful parameters are offered for customizing simulations.

Certain limitations of this work need to be considered in this section. For example, the provided tool is under continuous development to further include more and advanced functionalities, such as the straightforward use of fuzzy sets for FCM design, interval fuzzy values for weights, other efficient and state-of-the-art fuzzy methods (intuitionistic, type 2-fuzzy sets) for FCM model design, as well as other constraints on the concepts that constitute the aggregated FCM model.

Future work is directed towards further investigation of more scenarios and for different scientific domains. Moreover, for validation purposes, this method could be applied in a respective Renewable Energy domain, where more variables will be considered, while the producing results would be further analyzed and compared to those of the current study. Also, future work is devoted to the development of the data-based construction of FCMs where no qualitative or expert/stakeholder knowledge is available to design an FCM model for scenario analysis.

Author Contributions: Conceptualization, K.P.; methodology, K.P. and G.C.; software, K.P.; validation, K.P., G.C., E.I.P. and D.B.; formal analysis, K.P. and G.C.; investigation, K.P. and E.I.P.; resources, G.C.; data curation, G.C. and K.P.; writing - original draft preparation, K.P.; writing — review and editing, E.I.P. and D.B.; visualization, K.P.; supervision, E.I.P., and G.S.; project administration, E.I.P. and D.B. All authors have read and agreed to the published version of the manuscript.

Funding: This research received no external funding.

Conflicts of Interest: The authors declare no conflict of interest.

\section{References}

1. Kosko, B. Fuzzy cognitive maps. Int. J. Man Mach. Stud. 1986, 24, 65-75. [CrossRef]

2. Papageorgiou, E.I. Learning Algorithms for Fuzzy Cognitive Maps: A Review Study. IEEE Trans. Syst. Man Cybern. Part C 2012, 42, 150-163. [CrossRef]

3. Reckien, D.; Wildenberg, M.; Bachhofer, M. Subjective Realities of Climate Change: How Mental Maps of Impacts Deliver Socially Sensible Adaptation Options. Sustain. Sci. 2013, 8, 159-172. [CrossRef]

4. Groumpos, P.P. Fuzzy Cognitive Maps: Basic Theories and Their application to Complex Systems. Comput. Sci. 2010. [CrossRef]

5. Mateou, N.H.; Andreou, A.S. A framework for developing intelligent decision support systems using evolutionary fuzzy cognitive maps. J. Intell. Fuzzy Syst. 2008, 19, 151-170.

6. Papageorgiou, E.I. A new methodology for decisions in medical informatics using fuzzy cognitive maps based on fuzzy rule-extraction techniques. Appl. Soft Comput. 2011, 11, 500-513. [CrossRef]

7. Salmeron, J.L. Supporting decision makers with fuzzy cognitive maps. Res. Technol. Manag. 2009, 52, 53-59. [CrossRef]

8. Papageorgiou, E.I.; Papageorgiou, K.; Dikopoulou, Z.; Mouhrir, A. A web-based tool for Fuzzy Cognitive Map Modeling. In Proceedings of the 9th International Congress on Environmental Modelling and Software (iEMSs), Fort Collins, CO, USA, 24-28 June 2018.

9. Amer, M.; Jetter, A.; Daim, T. Development of fuzzy cognitive map (FCMs)-based scenarios for wind energy. Int. J. Energy Sect. Manag. 2011, 5, 564-584. [CrossRef]

10. Kok, K. The potential of Fuzzy Cognitive Maps for semi-quantitative scenario development, with an example from Brazil. Glob. Environ. Chang. 2009, 19, 122-133. [CrossRef]

11. Van Vliet, M.; Kok, K.; Veldkamp, T. Linking stakeholders and modelers in scenario studies: the use of Fuzzy Cognitive Maps as a communication and learning tool. Futures 2010, 42, 1-14. [CrossRef]

12. Jetter, A.; Schweinfort, W. Building scenarios with Fuzzy Cognitive Maps: An exploratory study of solar energy. Futures 2011, 43, 52-66. [CrossRef]

13. Karagiannis, I.E.; Groumpos, P.P. Modeling and analysis of a hybrid-energy system using fuzzy cognitive maps. In Proceedings of the 21st Mediterranean Conference on Control and Automation, Chania, Greece, 25-28 June 2013; pp. 257-264. 
14. Huang, S.; Lo, S.; Lin, Y. Application of a fuzzy cognitive map based on a structural equation model for the identification of limitations to the development of wind power. Energy Policy 2013, 63, 851-861. [CrossRef]

15. Ziv, G.; Watson, E.; Young, D.; Howard, D.C.; Larcom, S.T.; Tanentzap, A.J. The potential impact of Brexit on the energy, water and food nexus in the UK: a fuzzy cognitive mapping approach. Appl. Energy 2018, 210, 487-498. [CrossRef]

16. Schoemaker, P.J. Scenario planning: a tool for strategic thinking. Sloan Manag. Rev. 1995, 36, 25-50.

17. Stylios, C.; Groumpos, P.P. The challenge of modelling supervisory systems using fuzzy cognitive maps. J. Intell. Manuf. 1998, 9, 339-345. [CrossRef]

18. Azadeh, A.; Arab, R.; Behfard, S. An adaptive intelligent algorithm for forecasting long term gasoline demand estimation: The cases of USA, Canada, Japan, Kuwait and Iran. Expert Syst. Appl. 2010, 37, 7427-7437. [CrossRef]

19. Azadeh, A.; Saberi, M.; Gitiforouz, A.; Saberi, Z. A hybrid simulation adaptive-network-based fuzzy inference system for improvement of electricity consumption estimation. Expert Syst. Appl. 2009, 36, 11108-11117. [CrossRef]

20. Borrie, D.; Ozveren, C.S. The electric power market in the United Kingdom: Simulation with adaptive intelligent agents and the use of fuzzy cognitive maps as an inference engine. In Proceedings of the 39th International Universities Power Engineering Conference, 2004. UPEC 2004, Bristol, UK, 6-8 September 2004; Volume 3, pp. 1150-1154.

21. Hol, M.; Bilgin, A. Design of a Fuzzy Logic Based Framework for Comprehensive Anomaly Detection in Real-World Energy Consumption Data. In Benelux Conference on Artificial Intelligence; Springer: Cham, Switzerland, 2017; pp. 121-136.

22. Antosiewicz, M.; Nikas, A.; Szpor, A.; Witajewski-Baltvilks, J.; Doukas, H. Pathways for the transition of the Polish power sector and associated risks. Environ. Innov. Soc. Transit. 2019. [CrossRef]

23. Nikas, A.; Ntanos, E.; Doukas, H. A semi-quantitative modelling application for assessing energy efficiency strategies. Appl. Soft Comput. 2019, 76, 140-155. [CrossRef]

24. Nikas, A.; Doukas, H.; van der Gaast, W.; Szendrei, K. Expert views on low-carbon transition strategies for the Dutch solar sector: A delay-based fuzzy cognitive mapping approach. IFAC PapersOnLine 2018, 51, 715-720. [CrossRef]

25. Alipour, M.; Hafezi, R.; Papageorgiou, E.I.; Hafezi, M.; Alipour, M. Characteristics and scenarios of solar energy development in Iran: Fuzzy cognitive map-based approach. Renew. Sustain. Energy Rev. 2019, 116. [CrossRef]

26. Gray, S.A.; Gray, S.; Cox, L.J.; Henly-Shepard, S. Mental modeler: a fuzzy-logic cognitive mapping modeling tool for adaptive environmental management. In Proceedings of the 2013 46th Hawaii International Conference on System Sciences, Wailea, HI, USA, 7-10 January 2013; pp. 965-973.

27. Bachhofer, M.; Wildenberg, M. FCMappers-Disconnecting the Missing Link. Available online: http: //www.fcmappers.net/joomla/ (accessed on 10 February 2020).

28. Napoles, G.; Leon, M.; Grau, I.; Vanhoof, K. Fuzzy cognitive maps tool for scenario analysis and pattern classification. In Proceedings of the 2017 IEEE 29th International Conference on Tools with Artificial Intelligence (ICTAI), Boston, MA, USA, 6-8 November 2017; pp. 644-651.

29. Margaritis, M.; Stylios, C.; Groumpos, P.P. Fuzzy cognitive map software. In Proceedings of the 10th International Conference on Software, Telecommunications and Computer Networks SoftCom, Split, Dubrovnik, Croatia, Ancona, Venice, Italy, 8-11 October 2002; pp. 8-11.

30. De Franciscis, D. JFCM: a java library for FuzzyCognitive maps. In Fuzzy Cognitive Maps for Applied Sciences and Engineering; Springer: Berlin/Heidelberg, Germany, 2014; pp. 199-220.

31. Glykas, M. Fuzzy Cognitive Maps: Advances in Theory, Methodologies, Tools and Applications; Springer: Berlin/Heidelberg, Germany, 2010.

32. Papageorgiou, K.; Singh, P.K.; Papageorgiou, E.; Chudasama, H.; Bochtis, D.; Stamoulis, G. Fuzzy Cognitive Map-Based Sustainable Socio-Economic Development Planning for Rural Communities. Sustainability 2019, 12, 305. [CrossRef]

33. Singh, P.K.; Papageorgiou, K.; Chudasama, H.; Papageorgiou, E.I. Evaluating the Effectiveness of Climate Change Adaptations in the World's Largest Mangrove Ecosystem. Sustainability 2019, 11, 6655. [CrossRef] 
34. Trappey, A.J.C.; Trappey, C.V.; Hao, T.; Liu, P.H.Y.; Shin-Je, L.; Lin, L. The determinants of photovoltaic system costs: an evaluation using a hierarchical learning curve model. J. Clean. Prod. 2016, 112, 1709-1716. [CrossRef]

35. Ferreira, A.; Kunh, S.S.; Fagnani, K.C.; De Souza, T.A.; Tonezer, C.; Dos Santos, G.R.; Coimbra-Araújo, C.H. Economic overview of the use and production of photovoltaic solar energy in brazil. Renew. Sustain. Energy Rev. 2018, 81, 181-191. [CrossRef]

36. Papageorgiou, E.I.; Salmeron, J.L. Methods and Algorithms for Fuzzy Cognitive Map-based Modeling. Fuzzy Cogn. Maps Appl. Sci. Eng. 2014.

37. Papageorgiou, E.I.; Subramanian, J.; Karmegam, A.; Papandrianos, N. A risk management model for familial breast cancer: A new application using Fuzzy Cognitive Map method. Comput. Methods Programs Biomed. 2015, 122, 123-135. [CrossRef]

38. Nikas, A.; Doukas, H. Developing robust climate policies: a fuzzy cognitive map approach. In Robustness Analysis in Decision Aiding, Optimization, and Analytics; Springer: Berlin/Heidelberg, Germany, 2016; pp. 239-263.

39. Rocha, B.C.; Ferreira, P.P.F.V.; Dias, D.H.N.; Borba, B.S.M.C. Economic evaluation of photovoltaic microgenaration in the Southeast region of Brazil. In Proceedings of the 2018 Simposio Brasileiro de Sistemas Eletricos (SBSE), Niteroi, Brazil, 12-16 May 2018; pp. 1-6.

40. Lenz, A.M.; Colle, G.; de Souza, S.M.N.; Prior, M.; Nogueira, C.E.C.; Santos, R.F.; Friedrish, L.; Secco, D. Evaluation of three systems of solar thermal panel using low cost material, tested in Brazil. J. Clean. Prod. 2017, 167, 201-207. [CrossRef]

41. Martins, F.R.; Pereira, E.B.; Abreu, S.L. Satellite-derived solar resource maps for Brazil under SWERA project. Solar Energy 2007, 81, 517-528. [CrossRef]

42. Warren, B. Renewable Energy Country Attractiveness Index (RECAI); Ernst Young: London, UK, 2015.

43. Ministério de Minas e Energia (MME) Energia Solar no Brasil e no Mundo. Available online: http://gesel.ie. ufrj.br/app/webroot/files/IFES/BV/mme68.pdf (accessed on 2 October 2019).

44. Wang, Z.; Wei, W. External cost of photovoltaic oriented silicon production: a case in China. Energy Policy 2017, 107, 437-447. [CrossRef]

45. Zilli, B.; Miguel Lenz, A.; Souza, S.; Secco, D.; Nogueira, C.; Ando Junior, O.H.; Nadaleti, W.; Siqueira, J.; Gurgacz, F. Performance and effect of water-cooling on a microgeneration system of photovoltaic solar energy in Paraná, Brazil. J. Clean. Prod. 2018, 192. [CrossRef]

46. Paulo, A.F.; Porto, G.S. Evolution of collaborative networks of solar energy applied technologies. J. Clean. Prod. 2018, 204, 310-320. [CrossRef]

47. Schoemaker, P.J. When and how to use scenario planning: a heuristic approach with illustration. J. Forecast. 1991, 10, 549-564. [CrossRef]

48. Brown, R.G. Smoothing, Forecasting and Prediction of Discrete Time Series; Prentice-Hall: Englewood Cliffs, NJ, USA, 1963.

49. Özesmi, U.; Özesmi, L.O. Ecological models based on people's knowledge: a multi-step fuzzy cognitive mapping approach. Ecol. Model. 2004, 176, 43-64. [CrossRef]

50. Gray, S.R.J.; Gagnon, A.; Gray, S.; O’Dwyer, B.; O’Mahony, C.; Muir, D.; Devoy, R.J.N.; Falaleeva, M.; Gault, J. Are coastal managers detecting the problem? Assessing stakeholder perception of climate vulnerability using Fuzzy Cognitive Mapping. Ocean. Coast. Manag. 2014, 94, 74-89. [CrossRef]

51. Kosko, B. Neural Networks and Fuzzy Systems: A Dynamical Systems Approach to Machine Intelligence; Prentice-Hall, Inc.: Englewood Cliffs, NJ, USA, 1992; ISBN 0-13-612334-1.

52. Papageorgiou, E.; Kontogianni, A. Using Fuzzy Cognitive Mapping in Environmental Decision Making and Management: A Methodological Primer and an Application. In International Perspectives on Global Environmental Change; IntechOpen: London, UK, 2012; ISBN 978-953-307-815-1.

53. Holland, M. Fiscal crisis in Brazil: causes and remedy. Braz. J. Political Econ. 2019, 39. [CrossRef]

54. Nunes, F.; Melo, C.R. Impeachment, Political Crisis and Democracy in Brazil. Revista de Ciencia Política 2017, 37, 281-304. [CrossRef] 
55. International Labour Organization Labour Overview 2017, Latin America and the Caribbean; ILO Regional Office for Latin America and the Caribbean: Lima, Peru, 2017.

56. Torinelli, V.; Silva, A., Jr.; Souza, A.; Gomes, S.; Andrade, J. The impacts of environmental disasters on share value and sustainability index: an analysis of Vale company facing Mariana and Brumadinho disasters-Brazil. Latin Am. J. Manag. Sustain. Dev. 2020, 5, 75-94.

(C) 2020 by the authors. Licensee MDPI, Basel, Switzerland. This article is an open access article distributed under the terms and conditions of the Creative Commons Attribution (CC BY) license (http://creativecommons.org/licenses/by/4.0/). 